Discussion Paper No. 13-092

\title{
Estimation of Sectoral Elasticities of Substitution Along the International Technology Frontier
}

Claudio Baccianti

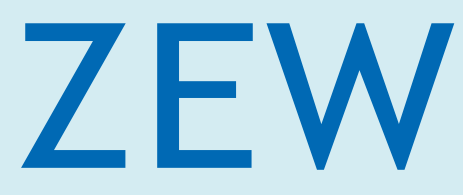

Zentrum für Europäische Wirtschaftsforschung $\mathrm{GmbH}$ Centre for European Economic Research 
Discussion Paper No. 13-092

\title{
Estimation of Sectoral Elasticities of Substitution Along the International Technology Frontier
}

\author{
Claudio Baccianti
}

Download this ZEW Discussion Paper from our ftp server:

http://ftp.zew.de/pub/zew-docs/dp/dp13092.pdf

Die Discussion Papers dienen einer möglichst schnellen Verbreitung von neueren Forschungsarbeiten des ZEW. Die Beiträge liegen in alleiniger Verantwortung der Autoren und stellen nicht notwendigerweise die Meinung des ZEW dar.

Discussion Papers are intended to make results of ZEW research promptly available to other economists in order to encourage discussion and suggestions for revisions. The authors are solely responsible for the contents which do not necessarily represent the opinion of the ZEW. 


\title{
Estimation of Sectoral Elasticities of Substitution along the International Technology Frontier
}

\author{
Claudio Baccianti*
}

\begin{abstract}
Sectoral heterogeneity is crucial to address several economic questions. This paper provides a detailed mapping of sectoral production possibility frontiers, using different nesting structures and levels of aggregation (primary, secondary, tertiary activities and energy-intensive firms). Elasticities of substitution between capital, labour and energy are identified by employing an international multisector dataset, accounting for biased technological change and normalising the production function to clusters of observations. Complementarity dominates, with the noteworthy exception of the capitallabour composite, close to Cobb-Douglas. I also present some stylized facts relating substitution elasticities to sectoral characteristics.
\end{abstract}

JEL Classification: C68, O14, O41, Q43

Keywords: Constant Elasticity of Substitution, Normalisation, Sectoral Disaggregation, Nested CES Structure, Energy Demand

*Centre for European Economic Research (ZEW), L7,1 68161 Mannheim, Germany (email: baccianti@zew.de). A previous version of this paper has been circulating with the title "Sectoral Production Technology and Conditions for Sustainability: an Empirical Investigation". I am grateful to Francois Laisney, Miguel Leon-Ledesma, Andreas Löschel, Benjamin Lutz, Kurt Kratena, Sascha Rexhäuser and Sjak Smulders for helpful comments and data support. 


\section{Introduction}

The estimation of sectoral production functions is relevant for several economic issues, from environmental sustainability of economic growth to the analysis of structural change and productivity. Clear-cut differences exist across sectoral groups of firms with respect to product features, production technology and business structure. A strand of macroeconomic research puts sectoral heterogeneity at the root of the structural change experienced by advanced economies in the last century. Besides differences in income elasticity of demand characterising sectoral goods, the rise and fall of the industrial sector has been due to sector-specific technological features, as higher total factor productivity and a larger scale of production compared to agriculture and services (Buera and Kaboski, 2012; Duarte and Restuccia, 2010). Another field which emphasises sectoral heterogeneity is the study of the environmental sustainability of economic growth. The industrial sector employs production technologies that have a higher pollution and natural resource intensity (e.g. chemical processes, furnaces, high-temperature processing) compared to lighter business activities as banking, accommodation and education services. Besides factor shares, the cross-price elasticity of substitution is a sectoral characteristic that has great importance in the literature, because the cost of environmental policies (taxes and quantity restrictions) in terms of output increases with the degree of complementarity of natural resources in production. The presence of sectors with a low intensity of natural resources and a degree of input substitution relieves such costs. Under an endogenous technological change framework, Bretschger and Smulders (2012) argue that the presence of highly innovative sectors that have complementarity between natural resources (or pollution) and other factors of production is a potential threat for long-run sustainability. If this was the case, resource scarcity would reduce the profitability of sectors with low flexibility in production and for those firms, investment in innovation would eventually dry up.

This paper delivers empirical evidence on production technology characteristics that sectors have in modern economies, with a special focus on elasticities of substitution between production inputs as capital, labour and energy. I provide a mapping of sectoral production possibility frontiers (PPFs), estimated with an international panel dataset of OECD economies and a quite detailed level of disaggregation. Jorgenson and Timmer (2011) recommend to dig into sectoral disaggregation because even the classic sectoral breakdown into primary, secondary and tertiary sectors is inaccurate when it comes to productivity. Whereas a large part of services has a sluggish productivity dynamics, an important fraction of tertiary firms (e.g. distribution services) does not differ much from industrial firms.

The literature on estimating PPFs spans over several decades and I refer to the extended surveys in Barker et al. (1995) and Chirinko (2008) for a detailed review. Surprisingly enough, even if the literature is extremely mature there is still need for further work. First of all, most studies have been interested in aggregate production functions and relatively little work has been done on the estimation of sectoral PPFs. Besides the interest arising from the strands of research mentioned above, high demand for this type of work comes from quantitative multi-sector general equilibrium models (e.g. Otto et al., 2008; van der Mensbrugghe, 2010), because the choice of parameter values describing production technologies usually relies on empirical work. By screening the literature in search of estimates for calibration of this type of models, I find that only some studies use a functional form that satisfies the regularity conditions they require (see Perroni and Rutherford 1995), like the CES production function. Moreover, the level of aggregation is important: model calibration needs to rely on data sharing similar underlying extensive margin (Browning et al., 1999). A recent study using sectoral data is Koesler and Schymura (2012). The paper presents estimates of sectoral Constant Elasticity of Substitution (CES) functions performed with non-linear estimation and alternative nesting structures, but factor-augmenting technological change is omitted and the PPF is identified without using factor demand equations.

In case the numerical or analytical model accounts for factor-augmenting technological change, good 
calibration standards - see Hansen and Heckman (1996) and Cooley (1997) for a discussion - require a satisfying match between the theoretical specification and the supporting empirical model. Only part of empirical studies in the literature embeds factor-biased technological progress. For calibration purposes, it is not recommended to use results from econometric work that only accounts for factors substitution if the model includes factor-augmenting technological change: the supporting econometric model should as well separately identify the marginal rate of technical substitution and the effect of technological change on inputs efficiency. The omission of biased technological progress might as well lead to flawed estimation results. Leon-Ledesma et al. (2013) show why neglecting factor-augmenting technological change in a CES production function estimation generates point estimates that are closer to the Cobb-Douglas value of one. Therefore, a general production function specification must be used in applied work even if dealing with biased technological change is not a straightforward task ${ }^{1}$.

Overall, the set of available empirical work using both sectoral data, CES production functions and factor-augmenting technology is tiny. The most relevant paper is the work by van der Werf (2008), who uses a general CES specification with factor-augmenting technological change. In his dataset the sectoral coverage is not extensive and the parameters of the production function are identified by first differencing. The application of first differences has the unpleasant side effect to remove important longrun information and to make the interpretation of the estimated elasticity less clear, as also remarked in Antras (2004).

My work contributes to the literature by providing estimates of sectoral production functions using a methodology that combines the points just mentioned and improves the identification of technology by normalising the production function (Leon-Ledesma et al., 2010). I obtain compelling empirical results about input substitution by using enough data variability and a general CES specification. The main data source is the World Input-Output Dataset (WIOD, Timmer (2012)), a multi-sector panel database with harmonised data for several countries. I prefer the panel estimation to the time-series approach of Antras (2004), Leon-Ledesma et al. (2010, 2013) and Herrendorf et al. (2013), because the joint use of cross-section and time-series variability improves the identification of input substitution and technological change. The estimation of the manufacturing sector's production function using only observations of the US manufacturing sector over time relies on the assumption that Italian, German, French and Canadian data for the same sector type are not informative to identify the manufacturing firm's production function. As I am interested in the general properties of the manufacturing sector's technology, it could be argued that the aggregate production function is better identified by looking at the variability across economies sharing similar technologies but having different characteristics. We need observations along the same isoquant and, this means, we need international data for the same sector type. Moreover, I apply the normalisation of the CES production function, which has several advantages for the case of interest. First, normalisation allows to properly identify all parameters of a CES specification with technological change and the normalised function does not have the unpleasant property that scale and distribution parameters are actually depending on the elasticity of substitution. Second, thanks to normalisation I overcome the underidentification problem well known in the literature and all coefficients in the resulting system of equations can be identified without using first-differences. Third, normalisation reshapes data variability: observations are normalized to a the collection of sectoral means (a representative country) and the separation of panels along the sector type dimension is less rough in terms of information loss.

\footnotetext{
${ }^{1}$ Carraro and De Cian (2012) is an attempt to account for the endogeneity of biased technological change. Using country data, they develop a framework that includes input substitution with a quite detailed representation of technological change, introducing some auxiliary variables to capture the microeconomic decisions of technology adoption, e.g. R\&D, education expenditures and equipment and machinery imports. This is an interesting approach because technological change is an elusive concept, an unobserved factor that should be represented in more details in econometric models. Alternatively, technological change can be treated as a time varying unobserved component and estimated with state-space models, as in Jin and Jorgenson (2010). They adopt a translog model, which is not fully compatible with applied models using CES functions.
} 
The focus is on input elasticities because the sample has a quite short time coverage (14 years) and the identification of long-run technological trends might be unsuccessful. The elasticity of substitution is considered to be quite stable over time and this analysis takes a snapshot of input substitution in the last two decades. Innovation and cross-country differences in technological development are only taken into account to correctly identify the elasticity of substitution. I find that production inputs are complements in most sectors and under several nesting structures, in line with previous studies, with a notable exception. The cross-price elasticity of substitution between capital and labour is close to unity, suggesting that value added sectoral production functions might be represented by a Cobb-Douglas specification.

Furthermore, I provide estimates for different levels of data aggregation. The WIOD dataset has a quite detailed level of sectoral disaggregation, up to two-digits, but some research questions call for a more aggregated grouping of firms according to characteristics as energy intensity or the type of output produced (i.e. raw materials, manufacturing goods or services). Not less important is the estimation of a classic economy-wide production function. When shifting the focus from one level of aggregation to another, a question comes natural: how does the elasticity of substitution depends on the level of aggregation? A strand of research with a theoretical focus has studied the microfoundation of the aggregate production function, explaining how particular statistical distributions of individual firms' production functions result in functional forms that are equivalent to Cobb Douglas and CES technologies (e.g. Jones (2005)). Under a more applied perspective, the works of Sato (1967) and, more recently, Oberfield and Raval (2012), explain the relationship between the aggregate elasticity of input substitution and the corresponding parameters of micro-production technologies. The aggregate elasticity of substitution is a weighted average of sectoral elasticities of substitution - the intensive margin - and the elasticity of demand between sectoral goods - the extensive margin. I find that the estimated elasticities for macrosectors lie within the range of estimates for subsectors, a hint that the extensive margin plays a little role compared to input share adjustment within narrow sectors.

The results of this paper give quite strong evidence for a below unit elasticity in the economy-wide production function, with the exception of the value added composite that maintains a unitary elasticity. By grouping sectors in macrosectors, i.e. primary/secondary/tertiary and energy-intensive/low energy use sectors, I obtain elasticity values that are quite similar across macrosectors. For significant heterogeneity in input substitution to appear, the level of disaggregation has to be higher. This result is relevant for building multisector models and it provides evidence for the modelling assumption of identical elasticities across broad sectoral groups. Moreover, the fact that the group of energy-intensive firms does not have a different degree of input substitution compared to the rest of the economy is particularly crucial for environmental policy.

The article is organised as follows. Section 2 is about the econometric methodology. After a brief description of the economic model, I introduce the theoretical underpinnings of the normalisation approach and explain how this is used to obtain a collection of panel datasets for different sectors. Estimation method and results are presented and discussed in Section 4. Section 5 concludes.

\section{Econometric Strategy}

In this section I present the identification strategy underlying the estimate of the sectoral elasticity of factor substitution, that is the percentage response of factor shares to input price changes in different countries, and factor-augmenting technological progress, shifts in factors efficiency that affect their marginal productivities. The econometric model is derived from the standard firm's maximisation problem. Firms' 
production is described by CES technology ${ }^{2}$ with factor-augmenting technological change and three inputs of production are employed, capital, labour and energy. Firms behave optimally in a competitive environment and substitution elasticities between inputs of production and factor-augmenting coefficients are identified through conditional factor demands obtained by Shephard's lemma. The non-normalised CES production function with capital $K$, labour $L$ and energy $E$ for one sector has the form:

$$
Y=\left[\pi\left(A_{K} K\right)^{\frac{\sigma-1}{\sigma}}+\omega\left(A_{L} L\right)^{\frac{\sigma-1}{\sigma}}+(1-\pi-\omega)\left(A_{E} E\right)^{\frac{\sigma-1}{\sigma}}\right]^{\frac{\sigma}{\sigma-1}},
$$

where $\pi$ and $\omega$ are share parameters and $A_{K}, A_{L}$ and $A_{E}$ are factor-augmenting coefficients of capital, labour and energy. After the derivation of conditional factor demands by Shepard's lemma and rearranging, the resulting equations for factor shares are

$$
\begin{aligned}
\ln \frac{K}{Y} & =\sigma \ln \pi+(\sigma-1) \ln A_{K}+\sigma \ln \frac{P_{Y}}{P_{K}}, \\
\ln \frac{L}{Y} & =\sigma \ln \omega+(\sigma-1) \ln A_{L}+\sigma \ln \frac{P_{Y}}{w}, \\
\ln \frac{E}{Y} & =\sigma \ln (1-\pi-\omega)+(\sigma-1) \ln A_{E}+\sigma \ln \frac{P_{Y}}{P_{E}},
\end{aligned}
$$

where $P_{Y}$ is the price of output and $P_{K}, P_{E}$ and $w$ are input prices. The use of energy complicates the interpretation of the model because gross output requires the use of intermediate goods, which are omitted here. In line with several papers in the literature I do not include intermediate goods, but I make the underlying assumption explicit. For model (2) - (4) to be a reliable foundation of the empirical analysis, intermediate goods should have a unitary elasticity of substitution with the capital-labourenergy composite in the production of gross output. Changes in relative prices of these inputs should induce little variation in the share of intermediate goods use ${ }^{3}$. In econometric terms, this is a classic case of omitted variable bias and capital, labour and energy prices are required not to be correlated with the intermediate goods share.

In the following, systems of factor demands - with one or two level functions - are going to be normalised to improve the identification of the PPF. Normalisation of the production function in empirical work needs a specific definition of the normalisation point in terms of available data. Before explaining how I normalise the panel dataset, I shortly digress on the meaning of normalisation and the implications for model (2) - (4). At the end of this section, the model is extended to the case of nested production functions.

\section{$2.1 \quad$ Normalisation}

Equation (1) is a constant elasticity of substitution production function in the most general formulation, given that the scale parameter - total factor productivity - is included in the share parameters thanks to the homogeneity of degree one of the function. Still, parameters in (1) may lack a clear economic interpretation. de La Grandville (1989) and Klump and de La Grandville (2000) point out that some parameters are in fact dependent on the elasticity of substitution $\sigma$ if variables are not normalised to a

\footnotetext{
2 Factor demands derived from CES functions are less general than alternative approaches (i.e. translog ) and this is not the best choice for an investigation on general properties of aggregate PPFs, but they have the advantage to satisfy regularity conditions required by applied economic modelling.

3 See Herrendorf et al. (2013) for a more detailed explanation of the conditions for a value added composite to exist. Even if here I am dealing with a capital-labour-energy composite and not a value added composite, the same reasoning holds.
} 
specific reference point. They show that the scale and distribution coefficients of a non-normalized CES production function are dependent on the elasticity of substitution, so that $\pi$ and $\omega$ in (1) change as $\sigma$ varies. From a theoretical viewpoint, the normalisation of the production function is recommended for comparative static exercises on $\sigma$ to make sure that an isoquant changes its curvature without shifting (the isoquant stays anchored to the normalisation point). As a result, a clearer economic interpretation can be attributed to each parameter in the normalised function ${ }^{4}$.

The production function (1) in normalised form is:

$$
\frac{Y}{Y_{0}}=\left[\pi_{0}\left(\frac{A_{K}}{A_{K 0}} \frac{K}{K_{0}}\right)^{\frac{\sigma-1}{\sigma}}+\omega_{0}\left(\frac{A_{L}}{A_{L 0}} \frac{L}{L_{0}}\right)^{\frac{\sigma-1}{\sigma}}+\left(1-\pi_{0}-\omega_{0}\right)\left(\frac{A_{E}}{A_{E 0}} \frac{E}{E_{0}}\right)^{\frac{\sigma-1}{\sigma}}\right]^{\frac{\sigma}{\sigma-1}}
$$

given the normalisation point $\left(Y_{0}, A_{K 0}, A_{L 0}, A_{E 0}, K_{0}, L_{0}, E_{0}, w_{0}, p_{k 0}, p_{e 0}\right)$. Similarly to the result in (2)(4), the system of conditional factor demands for capital, labour and energy is:

$$
\begin{aligned}
& \ln \frac{\bar{K}}{\bar{Y}}=(\sigma-1) \ln \bar{A}_{K}+\sigma\left(\ln \frac{\bar{P}_{Y}}{\bar{P}_{K}}+\ln \pi_{0}\right), \\
& \ln \frac{\bar{L}}{\bar{Y}}=(\sigma-1) \ln \bar{A}_{L}+\sigma\left(\ln \frac{\overline{P_{Y}}}{\bar{w}}+\ln \omega_{0}\right), \\
& \ln \frac{\bar{E}}{\bar{Y}}=(\sigma-1) \ln \bar{A}_{E}+\sigma\left(\ln \frac{\bar{P}_{Y}}{\bar{P}_{E}}+\ln \left(1-\pi_{0}-\delta_{0}\right)\right),
\end{aligned}
$$

where bar variables are normalized to the baseline point.

A well known problem in the literature (van der Werf, 2008; Carraro and De Cian, 2012) is that the estimation of system (2) - (4) cannot identify all unknown parameters $\sigma, A_{K}, A_{L}, A_{E}, \omega$ and $\pi$. The normalised system (6) - (8) has an advantage compared to system (2) - (4). When necessary, firstdifferencing may provide a solution by eliminating the distribution parameters $\omega$ and $\pi$ but the drawback is to limit the estimation results to the short-run. Normalisation of the production function (1) is able to make the system of factor demands fully identifiable, because share parameters have here a clear interpretation. The distribution parameters $\omega_{0}$ and $\pi_{0}$ in (5) are known, because they are the capital and labour shares at the normalisation point (i.e. $\left.\omega_{0}=\frac{w_{0} L_{0}}{w_{0} L_{0}+p_{E 0} E_{0}+p_{K 0} K_{0}}\right)$. The first term in the right hand side of (2)-(4) is constant and it may be added to relative prices (see (6) - (8)), meaning that for every observation the relative input price is adjusted to the corresponding factor share at the normalisation point. As a result, there are four unknown parameters $\sigma, \ln \bar{A}_{K}, \ln \bar{A}_{L}$, and $\ln \bar{A}_{E}$ that may be correctly identified without additional transformation applied on system (6)-(8).

\subsection{Normalisation with Panel Data}

The next step is to set a data counterpart for the normalisation point. Previous work applying normalisation (Leon-Ledesma et al., 2011, 2013; Herrendorf et al., 2013) has used time series data for one country - United States - and defined the normalisation point as the sample average over time. For the case of panel datasets the more complex data structure leaves room for alternative tuning of the normalised functions. The purpose of my study is to retrieve parameters of the sectoral production function describing sectoral PPFs. Normalising by time sample averages for each country-sector observation would rather be appropriate to estimate country-sector specific production functions and not general sectoral PPFs. Intuitively, observations that are represented by the same production function should have the same normalisation point.

\footnotetext{
${ }^{4}$ In the field of computational general equilibrium models, the normalised production function is called calibrated share form and this method is used to facilitate model calibration. At the baseline point the economy is in the benchmark scenario and the calibrated parameters should make the model replicate that reference point.
} 
Therefore, I choose to normalize the dataset with an average representative country, a vector of $J$ elements containing average values for each sector type $j \in\{1, \ldots, J\}$. Each observation is anchored to the relative sector-specific normalisation point for the first sample period. Alternatively, the dataset could be normalized with respect to one specific country, e.g. United States. In this case every Manufacturing sector observation has to be adjusted using the data for United States, the same for Agriculture and so on. If the chosen country is the most advanced in the world technology frontier the interpretation of estimated parameters would be clear, but with sectoral data it is not straightforward to find one country that is a technological leader in all sectors in the dataset. A more "anonymous" cross-section normalisation seems appropriate. Moreover, factor shares show low variability over time when data are aggregated by sector type and it produces more stable capital, labour and energy shares at the normalisation point. About the time position of the normalisation point (here equal to $t_{0}$ ), data show quite constant factor shares over the sample period so that the time dimension is not important for the implementation of normalisation. Following the literature using normalisation in applied work, the normalisation point is averaged over time.

Finally, notice that is is not necessary to find data for the normalisation of factor-augmenting coefficients $A_{h}$ for input $h$, because model (6)-(8) allows to estimate the normalised level of technology instead of the original parameter in (1). In fact, the normalisation of technology would not be straightforward because of its ambiguous nature, besides lack of data information and measurement issues. Therefore, the estimation results for factor-augmenting coefficients will measure the country relative position in the world technology frontier, the distance from the average level.

\subsection{Nested Production Functions}

Alternative specifications are important to provide results that are compatible with the specification of production structures commonly used in applied economic modeling, but the econometric strategy is not affected by nesting, nor aggregation. I consider four nesting cases: a one-level function and three two-level functions. As a major difference, the one-level function restricts the cross-price elasticity of substitution to be the same for alternative pairs of inputs, differently from the two-level nested functions. The estimation of different nesting specifications is mostly of interest for the calibration of specific numerical models and there is no convincing methodology to establish which nesting structure better fit the data ${ }^{5}$.

Systems of factor demands for production functions with alternative nesting structures are easily derived thanks to the weak separability of the CES function. For instance, the normalised CES function with $K L-E$ structure has the following specification:

$$
\frac{Y}{Y_{0}}=\left[\pi_{0}^{K L, E}\left(\frac{A_{V A}}{A_{V A 0}} \frac{V A}{V A_{0}}\right)^{\frac{\sigma_{K L, E}-1}{\sigma_{K L, E}}}+\left(1-\pi_{0}^{K L, E}\right)\left(\frac{A_{E}}{A_{E 0}} \frac{E}{E_{0}}\right)^{\frac{\sigma_{K L, E}-1}{\sigma_{K L, E}}}\right]^{\frac{\sigma_{K L, E}}{\sigma_{K L, E}-1}},
$$

with the value added term defined as:

$$
\frac{V A}{V A_{0}}=\left[\pi_{0}^{K, L}\left(\frac{A_{K}}{A_{K 0}} \frac{K}{K_{0}}\right)^{\frac{\sigma_{K, L}-1}{\sigma_{K, L}}}+\left(1-\pi_{0}^{K, L}\right)\left(\frac{A_{L}}{A_{L 0}} \frac{L}{L_{0}}\right)^{\frac{\sigma_{K, L}-1}{\sigma_{K, L}}}\right]^{\frac{\sigma_{K, L}}{\sigma_{K, L}-1}} .
$$

As in van der Werf (2008), the economic model used to estimate the nesting structure $K L-E$ is:

\footnotetext{
${ }^{5}$ Previous attempts to use a statistical criterion to select the nesting structure that better explain data (e.g. Kemfert (1998) and van der Werf (2008)) are not convincing. They compare factor demand systems with alternative nesting structures based on the $R^{2}$ statistics. However, these econometric models have different dependent variables, which makes the $R^{2}$ not suitable for such purpose.
} 


$$
\begin{aligned}
& \ln \frac{\bar{E}}{Y}=\left(\sigma_{K L, E}-1\right) \ln \bar{A}_{E}+\sigma_{K L, E}\left(\ln \frac{\overline{P_{Y}}}{P_{E}}+\ln \left(1-\pi_{0}^{K L, E}\right)\right) \\
& \ln \frac{\bar{w} \bar{L}}{\bar{P}_{V A} \overline{V A}}=\left(\sigma_{K, L}-1\right) \ln \bar{A}_{L} \bar{A}_{V A}+\sigma_{K, L} \ln \left(1-\pi_{0}^{K, L}\right)+\frac{\sigma_{K L, E}\left(\sigma_{K, L}-1\right)}{\sigma_{K L, E}-1} \ln \pi_{0}^{K L, E}+ \\
& +\frac{\left(\sigma_{K, L}-1\right)}{1-\sigma_{K L, E}} \ln \frac{\bar{P}_{V A} \overline{V A}}{P_{Y} Y}+\left(\sigma_{K, L}-1\right) \ln \frac{\bar{P}_{Y}}{\bar{w}} \\
& \ln \frac{\bar{P}_{K} \bar{K}}{\bar{P}_{V A} \overline{V A}}=\left(\sigma_{K, L}-1\right) \ln \bar{A}_{K} \bar{A}_{V A}+\sigma_{K, L} \ln \pi_{0}^{K, L}+\frac{\sigma_{K L, E}\left(\sigma_{K, L}-1\right)}{\sigma_{K L, E}-1} \ln \pi_{0}^{K L, E}+ \\
& +\frac{\left(\sigma_{K, L}-1\right)}{1-\sigma_{K L, E}} \ln \frac{\bar{P}_{V A} \overline{V A}}{P_{Y} Y}+\left(\sigma_{K, L}-1\right) \ln \frac{\bar{P}_{Y}}{\bar{P}_{K}} .
\end{aligned}
$$

Equations (12) and (13) include the share of value added over total output, given normalised prices and quantities. Differently from van der Werf (2008), rearranging conditional factor demands as in (12)(13) still does not help to overcome the problem of having unobservable variables of factor composites, i.e. $V A$, in the solution of profit maximisation given (9) - (10). In fact, equations (12) and (13) require to normalise separately prices and quantities of factor composites, which are not observed, so that I need to average these variables jointly and to consider only the value of the factor composite. This shortcut leads to measurement errors, due to the fact that averaging the value composite is not equal to the product of normalised prices and quantities $\left(\overline{P_{V A} V A} \neq \bar{P}_{V A} \overline{V A}\right)$. Nevertheless, the concern about potential estimation bias is limited if such error term, i.e. the covariance between prices and quantities, does not generate spurious variability across observations for each sector type. Over time, the covariance between prices and quantities in the same sector would be altered only if deep changes in the market structure occurred. However, the main assumption throughout the paper is that the PPF of each sector - which depends on the market structure - is constant over the sample time period, besides effects of technological change. The same holds for cross-country heterogeneity. As a result, consistently with the general working assumptions, I argue that the error introduced with the normalisation of factor composite variables does not generate bias in the estimation.

\section{Dataset Description}

My dataset covers 27 economies and 33 sectors, listed in Table 5 in the Appendix, for the period 19952008 and it is constructed with data from the World Input-Output Dataset (WIOD, see Timmer (2012)) and the IEA Energy Prices and Taxes database ${ }^{6}$. The WIOD provides information about output, input quantities, wages and capital prices for all sectors, based on the NACE classification (Rev 1.1). In particular, the WIOD contains data for quantities of energy use disaggregated by several energy carriers (26 energy carriers). The unit of measure for energy is tonnes of oil equivalent (toe). Labour price is the total labour compensation divided by labour units (total hours worked by individual engaged). The capital stock price is constructed using WIOD data and output is the real gross total output. The price of output at time $t_{0}$ is considered the numeraire for each sector-country observation. All nominal variables have been harmonized with appropriate exchange rates for prices and expressed in 1995 US

\footnotetext{
${ }^{6}$ The WIOD dataset includes data up to 2009 but the last year shows extreme drops in economic activity due to the aftermath of the 2007-2008 financial crisis and it is regarded as an outlier.
} 


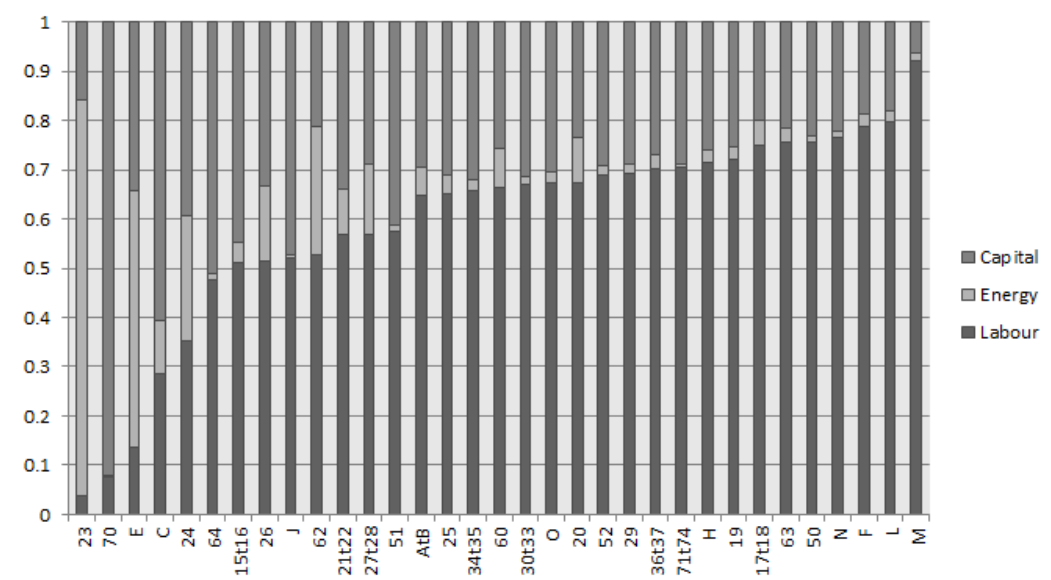

Figure 1: Factor Shares in the Disaggregated Dataset

Note: Sector labels are explained in Table 5 the Appendix

dollars. As no data on the price of energy composite are available from official sources, I construct energy price aggregates at country level by combining WIOD energy quantities with prices provided by the IEA dataset (the procedure is explained in more details in Appendix A). The IEA dataset does not include sectoral energy prices but only time-series of national price data are provided, so that in my dataset energy prices do not vary across sectors in the same country. The major concern related to such data limitation is that some sectors might face effective energy prices that are different from the national average, which may happen because, for instance, firms in these sectors bears special energy taxes or are relatively bigger compared to the size distribution in other sectors. Nevertheless, if this holds true in every country, each sectoral dataset used for estimation carries no particular flaw for estimation purpose.

Figure 1 shows input shares by sector, averaged over time and country dimension. Sectors are very heterogeneous with respect to factor shares: activities like production of fuels, real estate and mining have a low labour intensity and high capital intensity, whereas some service activities (e.g. education and public administration) and the construction sector have labour share well above 70 percent. Of course, such heterogeneity does not imply high diversity in the degree of input substitution. One important feature of the data is the stability of factor shares over time ${ }^{7}$ for each country-sector unit of observation, with no sharp variations over the sample time period. This fact is important because the normalisation point is fixed to one specific year and estimation results are likely to be robust to the choice of the benchmark time period.

Macrosectors are constructed by aggregation using groups of the original 33 sectors. Quantity variables are aggregated and prices are weighted averages of initial prices, with weights given by country-specific output shares on total international output. Details about sectoral aggregation are summarized in Table 6 in the Appendix. The first macrosectoral classification is based on the classic distinction between primary, secondary and tertiary sectors. The second classification separates the most energy-intensive activities from the rest of the economy. A sector is considered energy-intensive if the energy share on total costs is higher than 5 percent, on average ${ }^{8}$. This category includes agriculture, mining activities, some industries, the energy sector and transportation services. Finally, sectors are aggregated up to the national level to retrieve estimates of the classic macroeconomic production function.

\footnotetext{
${ }^{7}$ The time pattern of input shares for each country-sector unit cannot be displayed here for reasons of space.

${ }^{8}$ The choice of the threshold is quite robust, because by lowering it to $3 \%$ only one additional sector (Food, Beverages and Tobacco) would join the group of energy-intensive activities.
} 


\section{Estimation and Results}

\subsection{System Estimation}

Econometric models used to estimate one-level production possibilities frontiers (5) and two-level technologies, i.e. (9)-(10), are based on the normalised conditional factor demand models derived in the previous section. The econometric model is defined on a panel of country-year data, separately for each sector: I assume that each sector has the same degree of input substitution in different countries but levels of technological development are allowed to be heterogeneous across economies.

In order to capture the effect of time on technological progress and technology differences across countries, I focus on the growth rates of $\bar{A}_{h i}$, and assume that the normalised level of technology development

follows an exponential process $\bar{A}_{h i}=a_{h i} e^{\gamma_{h i}\left(t-t_{0}\right)}$, where $h$ is an input and $i$ a country index. Model (6)-(8) becomes:

$$
\begin{aligned}
\ln \frac{\bar{K}_{i t}}{\bar{Y}_{i t}} & =\alpha_{K i}+\delta_{K i}\left(t-t_{0}\right)+\beta \ln \left(\frac{\bar{P}_{Y_{i t}}}{P_{K_{i t}}} \pi_{0}\right)+\varepsilon_{i t}^{K} \\
\ln \frac{\bar{L}_{i t}}{\bar{Y}_{i t}} & =\alpha_{L i}+\delta_{L i}\left(t-t_{0}\right)+\beta \ln \left(\frac{\bar{P}_{Y_{i t}}}{\bar{P}_{L_{i t}}} \omega_{0}\right)+\varepsilon_{i t}^{L} \\
\ln \frac{\bar{E}_{i t}}{\bar{Y}_{i t}} & =\alpha_{E i}+\delta_{E i}\left(t-t_{0}\right)+\beta \ln \left(\frac{\bar{P}_{Y_{i t}}}{\bar{P}_{E_{i t}}}\left(1-\pi_{0}-\omega_{0}\right)\right)+\varepsilon_{i t}^{E}
\end{aligned}
$$

at time $t$, given $\alpha_{h i}=\ln a_{i}$ Sectoral indexes $j$ s are omitted for clarity. In vector notation $\left(\right.$ set $\left.t_{0}=0\right)$ :

$$
\overline{\mathbf{s}}_{i t}=\boldsymbol{\alpha}_{\boldsymbol{i}}+\boldsymbol{\delta}_{\boldsymbol{i}} t+\overline{\mathbf{P}}_{i t} \beta+\varepsilon_{i t}
$$

where the $3 x 1$ vector $\overline{\mathbf{s}}_{i t}$ contains physical input shares and $\overline{\mathbf{P}}_{i t}$ is a $3 x 1$ vector of normalised relative prices. All models are estimated with the generalised method of moments estimator. The variancecovariance matrix of disturbances is Heteroskedasticity and Autocorrelation Consistent (HAC) to account for autocorrelation typical of macroeconomic variables (and present in the data here). No specific assumption is imposed on the cross-equation error correlation. Notice that sectoral input-output relationships could spur serial correlation in the error terms across sector, but this is not an issue here because model (17) is specified for one single sector.

The vector $\boldsymbol{\alpha}_{\boldsymbol{i}}$ of factor-augmenting technological change coefficients measures the initial level of technology development for country $i$. To understand whether $\boldsymbol{\alpha}_{\boldsymbol{i}}$ is better captured by fixed or random effects, I carry out classic tests to compare alternative panel data models. Firstly, the Likelihood Ratio test rejects complete pooling meaning that fixed effects improve the identification of the sectoral degree of input substitution. Secondly, the Hausman test supports the fixed effects model as candidate for further estimation.

Model (17) accounts for country-specific factor-augmenting technological change and for each input it captures both level, by a constant term, and rate of efficiency growth, by a time trend. The former term measures the starting position of the country on the - normalised - international technology frontier and the latter would instead catch dynamic features of factor-augmenting technology, namely changes in factor intensity over time. Parameter estimates of system (17) are used to retrieve the coefficients of the original model, the elasticity of substitution $\sigma$ and growth rates $\gamma_{h i}$. Here I focus on the estimates of elasticities and leave aside results for factor-augmenting coefficients. Besides the data short time coverage, notice that in the two-level production functions the interpretation of technological change coefficients for composites of inputs, see system (11) - (13), does not provide insights on more general questions on the nature of technological change. The elasticity of substitution is obtained as $\hat{\sigma}=\hat{\beta}$, where $\hat{\beta}$ is the 
coefficient estimated from model (17).

The estimation of two-level factor demand systems, as (11) - (13), is similar. The estimated system of equation is:

$$
\begin{gathered}
\ln \frac{\overline{\bar{Y}}}{\bar{Y}}=\alpha_{E i}+\delta_{E i}\left(t-t_{0}\right)+\beta_{1} \ln \left(\frac{\bar{P}_{Y_{i t}}}{\bar{P}_{E_{i t}}}\left(1-\pi_{0}^{K L, E}\right)\right)+\epsilon_{i t}^{E} \\
\ln \frac{\bar{w} \bar{L}}{\bar{P}_{V A} \overline{V A}}=\alpha_{V A-L, i}+\delta_{V A-L, i}\left(t-t_{0}\right)+\frac{\beta_{2}}{1-\beta_{1}} \ln \frac{\bar{P}_{V A} \overline{V A}}{P_{Y} \bar{Y}}+\beta_{2} \ln \frac{\bar{P}_{Y}}{\bar{w}}+\epsilon_{i t}^{V A-L}, \\
\ln \frac{\bar{P}_{K} \bar{K}}{\bar{P}_{V A} \overline{V A}}=\alpha_{V A-K, i}+\delta_{V A-K, i}\left(t-t_{0}\right)+\frac{\beta_{2}}{1-\beta_{1}} \ln \frac{\bar{P}_{V A} \overline{V A}}{\bar{P}_{Y} \bar{Y}}+\beta_{2} \ln \frac{\bar{P}_{Y}}{\bar{P}_{K}}+\epsilon_{i t}^{V A-K} .
\end{gathered}
$$

Again, I set $t=t_{0}$ and carry out the estimation with the generalised method of moments estimator with HAC variance-covariance matrix. Also in this case country-specific coefficients are modeled as fixed effects. Thanks to restrictions imposed on coefficients before estimation, the elasticities of substitution are retrieved as follows: $\hat{\sigma}_{K L, E}=\hat{\beta}_{1}$ and $\hat{\sigma}_{K, L}=\hat{\beta}_{2}$.

\subsection{Estimation Results}

\subsubsection{Alternative Nesting Structures}

This section presents a general discussion of the results obtained with the most disaggregated data and tables showing full details ${ }^{9}$ are attached in the Appendix (Tables 8 and 9). Estimation results for the four nesting structures provide strong evidence for input complementarity in production, in line with the literature. Table 1 lists some descriptive statistics for the point estimates (if statistically significant at 5 percent), in order to give a flavour of the distribution of $\sigma$ across sectors. Figure 2 plots some of the estimated elasticities for all sectors, ordered by value. The $K L E$ one-level production function constraints substitution possibilities to be the same for capital, labour and energy and in this case, results point quite clearly at complementarity between them. Only three sectors (Agriculture, Machinery and Wholesale Trade) have an estimated elasticity $\hat{\sigma}_{K L E}$ that is not significantly different from one at the $5 \%$ level. For two-level production functions, results show a quite high heterogeneity in sectoral substitution between inputs. When capital and labour are combined in a value added composite (the $K L-E$ nesting), sectoral elasticities between the two inputs lie quite close to unity and for some manufacturing sectors and transportation activities, the value added composite is described by a Cobb-Douglas production function. This result is remarkable, providing evidence for the common modelling assumption of fixed labour and capital compensation shares. Differently from studies that focus on capital and labour only, here the econometric model accounts for the effect of the upper nesting level (energy) in the substitution between capital and labour. Equations (19)-(20) in Section 4.1 show how the upper-level elasticity $\sigma_{K L, E}$ enters factor demands and alters the effect of changes in the share of value added on labour and capital shares. Looking at the distribution of $\hat{\sigma}_{K, L}$, mean and median values are slightly below unity, whereas energy shows a high degree of complementarity with the value added composite. Intuitively, large part of the energy demand derives from the use of capital goods and complementarity was expected. This intuition is confirmed by $\hat{\sigma}_{K, E}$ in the $K E-L$ nesting, point estimates that indicate low flexibility in the use of capital and energy (with the unique exception of the Wood Production sector).

Elasticity distributions are rather symmetric and mean and median values stay within the domain of complementarity. The estimated elasticity is higher than one only in few cases, mostly in the $L E-K$ nesting. For several sectors, about one third, the $L E-K$ structure has high substitution between capital

\footnotetext{
${ }^{9}$ Due to limitations of space, Tables 8-9 do not report additional tests ( $J$-statistic and parameter tests) but they are avalable upon request.
} 
Table 1: Estimated Elasticities for Disaggregated Sectors

\begin{tabular}{cccccccc} 
& \multicolumn{2}{c}{$K L-E$} & \multicolumn{2}{c}{$K E-L$} & \multicolumn{2}{c}{$L E-K$} & \multicolumn{1}{c}{$K L E$} \\
\cline { 2 - 7 } & $\hat{\sigma}_{K L, E}$ & $\hat{\sigma}_{K, L}$ & $\hat{\sigma}_{K E, L}$ & $\hat{\sigma}_{K, E}$ & $\hat{\sigma}_{L E, K}$ & $\hat{\sigma}_{L, E}$ & $\hat{\sigma}_{K L E}$ \\
\hline [Min - Max] & {$[0-0.82]$} & {$[0.59-1.05]$} & {$[0-1.31]$} & {$[0.36-1.03]$} & {$[0-1.96]$} & {$[0.20-0.87]$} & {$[0.39-0.89]$} \\
Mean & 0.25 & 0.91 & 0.38 & 0.57 & 0.72 & 0.65 & 0.73 \\
Median & 0.25 & 0.93 & 0.40 & 0.54 & 0.53 & 0.67 & 0.75 \\
\hline
\end{tabular}

Note: 337 observations. Non-zero values are estimated coefficients with level of significance at $5 \%$.

and the labour-energy composite, but at the same time in half of the sectors a Leontief technology results. The distribution of $\hat{\sigma}_{L E, K}$ is indeed quite asymmetric and the median is lower than the mean.

Yet we might doubt that if a sector had a Cobb-Douglas technology but different factor shares across countries, the econometric strategy used here could lead to flawed results because of the normalisation of the share parameters in the production function. Here the share parameter - crucial in a CobbDouglas function - is indeed constrained to be equal to the input share at the normalisation point, but cross-country heterogeneity in factor shares could be still captured by fixed effects and no bias arises in the estimation of the elasticity parameter. In this regard, the time dimension of the panel dataset is particularly important to disentangle these data features, given quite stable factor shares over time.

In Figure 2, sectors are ordered by their estimated elasticity value for the one-level production function $\hat{\sigma}_{K L E}$ and for input couples in various two-level production nestings $\left(\hat{\sigma}_{K, L}, \hat{\sigma}_{K, E}, \hat{\sigma}_{L, E}\right)$. Is the ranking depending on sectoral characteristics? This question is rather unusual, because the elasticity of substitution between inputs is regarded as an - unexplained - exogenous parameter. Looking at the graphs, sectors' placement on the ranking does not show any apparent regularity, but a more accurate analysis provides interesting insights. I calculate correlations of sectoral elasticities with selected sectoral characteristics, reported in Table 2, and find some "stylised facts".

First, the elasticity of substitution $\hat{\sigma}_{K L E}$ in the one-level production function is correlated with input cost shares $\psi_{h}, h \in\{L, K, E\}$, positively with the labour share and negatively with the fraction of capital and energy costs. For $\hat{\sigma}_{K, L}$ the opposite holds, which gives a hint about the role of factoraugmenting technological change in the relationship (that is ineffective on cost shares under Cobb-Douglas technology). The fourth column shows the correlation of $\hat{\sigma}_{f}$ with a measure of the imbalance in factor shares, $\phi_{H}^{j}=\left|\psi_{h_{1}}^{j}-\left(\sum_{h}^{H} \psi_{h}^{j}\right) / N_{H}\right|$, where $H$ is the set of $N_{H}$ inputs in the nesting and $\psi_{h_{1}}$ is the factor cost share of one of these inputs. Except for the $K L$ composite, in the other three forms of nesting the elasticity is weakly correlated with the imbalance in factor use. The fifth columns shows no signs of a strong relationship between input substitution and the size of the sector $j$ market, measured by the value share on total national output, $\nu_{j}$. The last three columns present correlations between $\sigma$ and $\theta_{h}^{j}$, the fraction of total national employment of input $h$ that is demanded by sector $j$. The statistically significant correlation coefficients are mostly negative, in particular for the one-level production function.

Overall, this piece of analysis sheds some light on the ranking in Figure 2. Consider the graph representing the elasticity $\sigma_{K L E}$ at the bottom of the page. According to the correlations of Table 2, sectors with high elasticity values tend to have higher labour cost shares - and more imbalanced input shares - but also to be small players in factor markets. The presence of non zero correlations between cross-price input elasticities and sectoral equilibrium allocations has important implications for economic policy because the effect of an input tax depends on such kind of correlation in an economy with several heterogeneous sectors. 

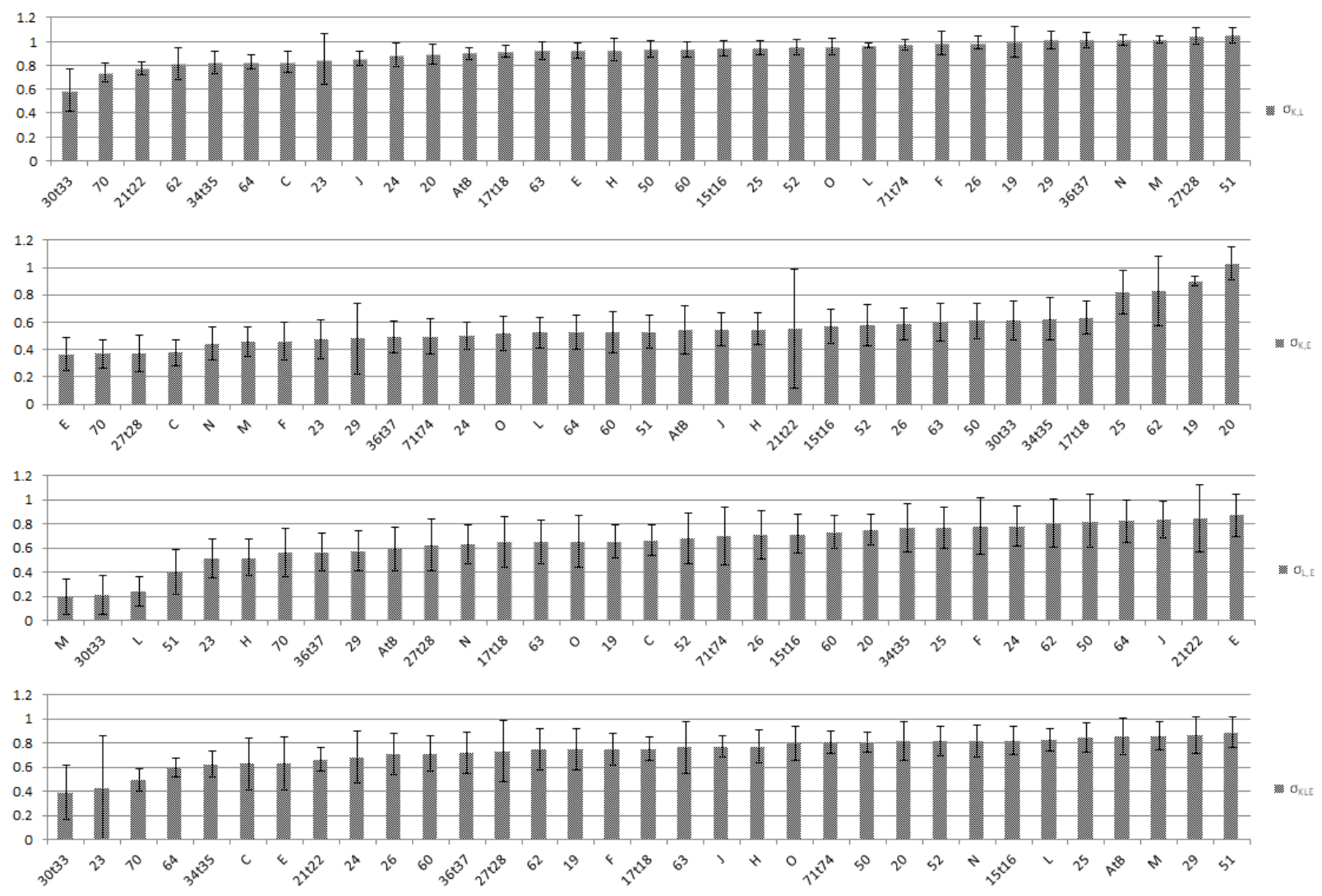

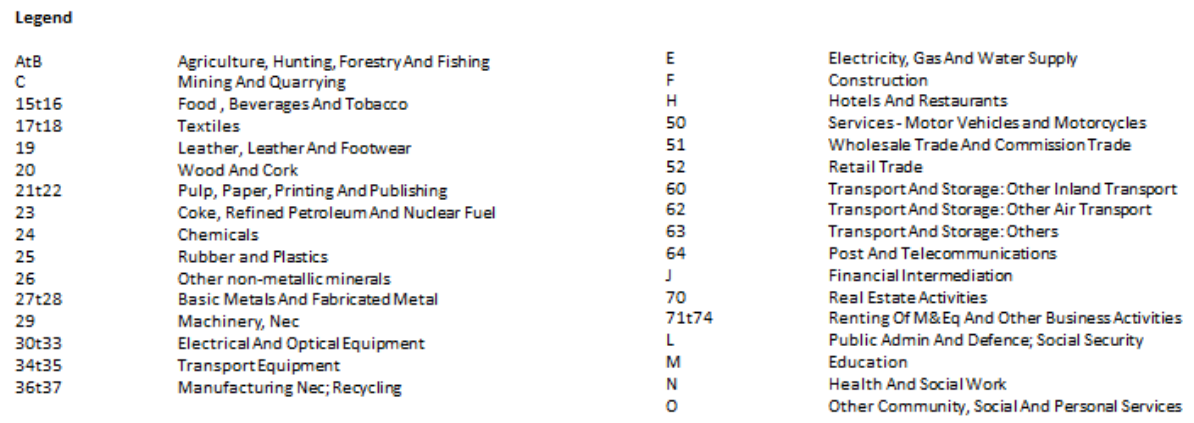

Figure 2: Overview of Sectoral Elasticities of Substitution Note: Confidence intervals at $95 \%$ level. 
Table 2: Correlation between Input Elasticities and Sectoral Characteristics

\begin{tabular}{ccccccccc} 
& & $\begin{array}{c}\text { Cost } \\
\text { Shares }\end{array}$ & & $\begin{array}{c}\text { Input Share } \\
\text { Imbalance }\end{array}$ & $\begin{array}{c}\text { Sector } \\
\text { Value Share }\end{array}$ & \multicolumn{3}{c}{$\begin{array}{c}\text { Sector Weight } \\
\text { in Input's Market }\end{array}$} \\
\hline$\rho$ & $\psi_{L}$ & $\psi_{K}$ & $\psi_{E}$ & $\phi_{H}$ & $\nu$ & $\theta_{L}$ & $\theta_{K}$ & $\theta_{E}$ \\
\hline$\hat{\sigma}_{K, L}$ & $\mathbf{0 . 4 1}$ & $\mathbf{0 . 4 0}$ & - & 0.13 & -0.02 & $\mathbf{0 . 3 7}$ & -0.28 & -0.063 \\
& 0.016 & 0.019 & & 0.478 & 0.924 & 0.036 & 0.118 & 0.729 \\
$\hat{\sigma}_{K, E}$ & - & -0.29 & -0.16 & -0.31 & $\mathbf{- 0 . 4 0}$ & -0.28 & -0.33 & -0.29 \\
& & 0.110 & 0.398 & 0.076 & 0.022 & 0.112 & 0.062 & 0.104 \\
$\hat{\sigma}_{L, E}$ & -0.25 & - & 0.13 & $\mathbf{- 0 . 3 8}$ & -0.28 & -0.33 & -0.16 & 0.11 \\
& 0.181 & & 0.485 & 0.027 & 0.115 & 0.058 & 0.379 & 0.560 \\
$\hat{\sigma}_{K L E}$ & $\mathbf{0 . 6 4}$ & $\mathbf{- 0 . 3 7}$ & $\mathbf{- 0 . 4 6}$ & 0.34 & 0.04 & $\mathbf{- 0 . 6 7}$ & -0.30 & $\mathbf{- 0 . 4 4}$ \\
& 0.000 & 0.042 & 0.008 & 0.057 & 0.815 & 0.000 & 0.091 & 0.011 \\
\hline
\end{tabular}

Note: p-values in smaller font, bold faced values are statistically significant at 5 percent level.

\subsubsection{Level of Aggregation and Elasticities}

Table 3 shows estimation results and reports distribution statistics ${ }^{10}$ for $n_{j}$ subsectors that belong to each macrosector $j \in\{$ Pri,Sec,Ter, HighE,LowE, Aggr $\}$ (see Table 6 in the Appendix for details). In general, complementarity is confirmed at a higher level of aggregation. Qualitatively, the Primary, Secondary and Tertiary sectors do not differ much in terms of input substitution for all nesting structures except $\hat{\sigma}_{L E, K}$. The estimates for $\hat{\sigma}_{L E, K}$ show perfect complementarity between labour and the $K E$ composite in the Primary and Secondary sectors and, consistently, for Energy-Intensive firms. On the contrary, the Tertiary sector (as well as the Low Energy Use sector) appears to have strong degree of substitution at this level of the nesting. The results would bolster the assumption of identical degree of input substitution across sectors, common in theoretical modelling work. Qualitatively, sectors differ with respect to factor shares but not the elasticity of substitution.

Moreover, even the estimation with macrosector data provides support for a unitary elasticity between capital and labour in the $K L$ composite, which is in contrast with previous studies using normalised production functions, i.e. Herrendorf et al. (2013) and Leon-Ledesma et al. (2013). Obtaining higher results than studies using time-series data is not a new issue in the literature - see Antras (2004) for a discussion - but my work embeds two major improvements compared to these studies: the extension to a panel data analysis and the modelling of energy. By accounting for energy, I manage to capture the interactions between this input and capital and labour and go beyond the implicit assumption of fixed cost shares between energy and the value added composite. Another enhancement comes from the cross-section dimension because there are additional information to estimate the technology frontier of each country. However, my estimates mostly differ from Herrendorf et al. (2013) and Leon-Ledesma et al. (2013) because I estimate an international PPF rather than the degree of input substitution for one single country, that in their case is United States.

My results bring a bad news for environmental policy: energy-intensive firms have strong complementarity between energy and other factors of production. Without technological progress, environmental policies relying on input substitution have little potential to reduce firms energy demand without occurring in high output losses. Related to the insight of Bretschger and Smulders (2012), input complementarity in production for the most innovative firms, namely the Secondary sector, arises the concern that energy scarcity might have detrimental effects on the pace of technological change.

Input elasticities at a more aggregated level are expected to differ from estimates discussed in the previous section. For instance, data variation for relative input prices and quantity shares in the energyintensive sector embodies both the degree of input substitution of subsectors and the extensive margin

\footnotetext{
${ }^{10}$ As the Primary sector includes only the Agriculture and Mining sectors, no mean and median values are calculated.
} 
Table 3: Estimated Elasticities for Macrosectors and Comparison

\begin{tabular}{|c|c|c|c|c|c|c|c|}
\hline & \multicolumn{2}{|c|}{$K L-E$} & \multicolumn{2}{|c|}{$K E-L$} & \multicolumn{2}{|c|}{$L E-K$} & \multirow{2}{*}{$\frac{K L E}{\hat{\sigma}_{K L E}}$} \\
\hline & $\hat{\sigma}_{K L, E}$ & $\hat{\sigma}_{K, L}$ & $\hat{\sigma}_{K E, L}$ & $\hat{\sigma}_{K, E}$ & $\hat{\sigma}_{L E, K}$ & $\hat{\sigma}_{L, E}$ & \\
\hline $\begin{array}{l}\text { Primary } \\
\left(n_{P r i}=2\right)\end{array}$ & 0.28 & 0.91 & 0.29 & 0.46 & 0 & 0.62 & 0.87 \\
\hline [Min-Max] & {$[0.27-0.29]$} & {$[0.83-0.90]$} & {$[0-0.40]$} & {$[0.38-0.54]$} & {$[0-0]$} & {$[0.59-0.67]$} & {$[0.39-0.86]$} \\
\hline Mean/Median & - & - & - & - & - & - & - \\
\hline $\begin{array}{l}\text { Secondary } \\
\left(n_{S e c}=16\right)\end{array}$ & 0.23 & 0.95 & 0.25 & 0.53 & 0 & 0.56 & 0.62 \\
\hline [Min-Max] & {$[0-0.32]$} & {$[0.59-1.04]$} & {$[0-1.31]$} & {$[0.36-1.03]$} & {$[0-1.95]$} & {$[0.21-0.87]$} & {$[0.49-0.89]$} \\
\hline Mean/Median & $0.21 / 0.24$ & $0.91 / 0.93$ & $0.37 / 0.39$ & $0.59 / 0.56$ & $0.67 / 0.41$ & $0.68 / 0.71$ & $0.70 / 0.73$ \\
\hline $\begin{array}{c}\text { Tertiary } \\
\left(n_{T e r}=15\right)\end{array}$ & 0.20 & 1.00 & 0.42 & 0.45 & 1.67 & 0.66 & 0.82 \\
\hline [Min-Max] & {$[0.17-0.82]$} & {$[0.73-1.05]$} & {$[0-0.73]$} & {$[0.37-0.82]$} & {$[0-1.96]$} & {$[0.19-0.84]$} & {$[0.49-0.89]$} \\
\hline Mean/Median & $0.28 / 0.25$ & $0.92 / 0.93$ & $0.42 / 0.42$ & $0.54 / 0.53$ & $0.86 / 0.85$ & $0.62 / 0.65$ & $0.77 / 0.80$ \\
\hline $\begin{array}{c}\text { Energy-Intensive } \\
\left(n_{H i g h E}=11\right)\end{array}$ & 0.21 & 0.95 & 0.26 & 0.44 & 0 & 0.59 & 0.66 \\
\hline [Min-Max] & {$[0-0.82]$} & {$[0.77-1.04]$} & {$[0-1.31]$} & {$[0.36-1.03]$} & {$[0-1.85]$} & {$[0.52-0.87]$} & {$[0.43-0.82]$} \\
\hline Mean/Median & $0.27 / 0.25$ & $0.90 / 0.92$ & $0.42 / 0.44$ & $0.59 / 0.55$ & $0.44 / 0$ & $0.72 / 0.73$ & $0.70 / 0.71$ \\
\hline $\begin{array}{c}\text { Low Energy Use } \\
\left(n_{\text {LowE }}=22\right)\end{array}$ & 0.21 & 0.99 & 0.33 & 0.47 & 1.51 & 0.64 & 0.75 \\
\hline [Min-Max] & {$[0-0.30]$} & {$[0.59-1.05]$} & {$[0-0.76]$} & {$[0.37-0.9]$} & {$[0-1.96]$} & {$[0.20-0.84]$} & {$[0.39-0.89]$} \\
\hline Mean/Median & $0.23 / 0.25$ & $0.92 / 0.95$ & $0.36 / 0.39$ & $0.55 / 0.53$ & $0.87 / 0.85$ & $0.61 / 0.65$ & $0.75 / 0.80$ \\
\hline $\begin{array}{c}\text { Aggregate Economy } \\
\left(n_{\text {Aggr }}=33\right)\end{array}$ & 0.21 & 0.98 & 0.31 & 0.42 & 1.51 & 0.73 & 0.74 \\
\hline [Min-Max] & {$[0-0.81]$} & {$[0.59-1.05]$} & {$[0-1.31]$} & {$[0.36-1.03]$} & {$[0-1.96]$} & {$[0.19-0.87]$} & {$[0.39-0.89]$} \\
\hline Mean/Median & $0.25 / 0.25$ & $0.91 / 0.93$ & $0.38 / 0.40$ & $0.57 / 0.54$ & $0.72 / 0.53$ & $0.65 / 0.67$ & $0.73 / 0.75$ \\
\hline
\end{tabular}

Note: 337 observations. Non-zero values are estimated coefficients with level of significance at $5 \%$.

adjustment operating through reallocation of demand across sectoral goods. In fact, subsectors differ in factor shares and their output prices react differently to input price changes. According to the theoretical understanding of Sato (1967) and Oberfield and Raval (2012), having point estimates for macrosectors lying within the minimum and maximum value of subsector elasticities hints that the elasticity of demand between subsector goods is quite low. This result is not trivial as for different types of elasticities, i.e. Frisch elasticity of labour supply, the aggregate value turns to be higher than estimates from micro-data because the extensive margin plays a more important role (total hours mostly adjust through employment changes, see for instance Fiorito and Zanella (2012)).

\subsection{Robustness Check}

Compared to most studies to date, the normalisation approach has the advantage to leave room for the analysis of long-run dynamics. Indeed, systems (14) - (16) and (18) - (20) can identify all coefficients of the original model with variables in levels and do not require first differencing. Nonetheless, the use of level variables with time series data raises the well known concern about spurious regression. In the case at hand, even testing for the presence of unit roots is not a straightforward task because of the complex data structure and the small sample time length $T$. Unfortunately, with $T=14$ and $N=27$ panel unit-root tests, like the Im-Pesaran-Shin test, have low power and size distortion (Maddala and Wu, 1999; Im et al., 2003). In order to avoid the use of unreliable evidence, an indirect way to check for spurious estimation, I make additional estimation runs with a first-differenced version of the factor demand models. Results are shown in Tables 9 and Table 11 in the Appendix. Overall, the use of first differences leads to outcomes that are qualitatively similar to the results of the previous set of estimations, even if they 
Table 4: Changes in Sectoral Ranking with the First-differenced Model

\begin{tabular}{ccccc}
$\mid \triangle$ Quartile $\mid$ & $\hat{\sigma}_{K, L}$ & $\hat{\sigma}_{K, E}$ & $\hat{\sigma}_{L, E}$ & $\hat{\sigma}_{K L E}$ \\
\hline Zero & 13 & 14 & 6 & 10 \\
One & 10 & 11 & 10 & 14 \\
Two & 7 & 5 & 11 & 6 \\
Three & 3 & 3 & 6 & 3 \\
\hline
\end{tabular}

might be quantitatively different. Firstly, the evidence for gross complementarity between capital, labour and energy still holds. For some sectors the estimated elasticity of substitution is lower than previously estimated and drops to zero. Secondly, new estimates still indicate that the elasticity of substitution between capital and labour in the $K L-E$ production structure is close to one at various levels of aggregation. Third, I check if the ranking over $\hat{\sigma}^{j}$ is preserved. I divide the set of estimation results for each nesting structure into four quartiles, with thresholds given by the 25th, 50th, 75th percentiles of the sample distribution of estimated input elasticities. For each sector, I track the change in quartile position after estimating the corresponding first-differenced model, which can be from -3 to +3 . Table 4 shows the number of sectors that happen to have one, two, three or no changes in quartile in the new set of estimates. I consider the position in the order preserved if the sector does not jump to another quartile and we can see from Table 4 that this strict condition holds only in one third of the estimation results. Under a more relaxed requirement that allows the sector's $\hat{\sigma}^{j}$ to jump in one of the closest quartiles, the distribution looks quite preserved eventually for all elasticities except $\hat{\sigma}_{L, E}$. The ordering of sectors along the $\hat{\sigma}_{L, E}$ estimates is rather different from the one obtained from the estimation without first-differenced variables.

\section{Final Remarks}

I have presented estimates of the elasticity of substitution between capital, labour and energy obtained from the estimation of normalised conditional factor demands with cross-country panel datasets. The normalisation of the production function and the rich dataset help to identify factor-augmenting technological change and to measure the degree of factor substitution more precisely. The estimation is carried out on alternative input nesting structures and different levels of aggregation.

There are four major findings. First, in line with previous studies, there is a quite low degree of flexibility in using production inputs at the aggregate level. Given a one percent change in relative input prices, factor shares experience a less than proportional percentage variation. In a CES specification, this also implies an increase in the cost share of the input that gets relatively more expensive. Moreover, higher input efficiency through factor-augmenting technological progress has the effect to reduce the input marginal productivity and shrink the relative demand of this production factor. This result holds in most sectors under different levels of aggregation and alternative nesting structures. The notable exception is capital and labour in the value added composite. In this case the cross-price elasticity of substitution is close to unity and this result suggests that production functions for sectoral value added might be represented by a Cobb-Douglas specification. Second, by grouping sectors in macrosectors, i.e. primary/secondary/tertiary and energy-intensive/low energy use sectors, I obtain elasticity values that are quite similar across macrosectors. Moreover, the group of energy-intensive firms does not have a different degree of input substitution compared to the rest of the economy. As well, the primary, secondary and tertiary sectors have very similar elasticities. The full data aggregation up to the national economy provides estimates of the classic aggregate production function and shows a quite strong evidence for an elasticity below unit with the exception, also in this case, of the value added composite that results to have a unitary elasticity. The third result is that the estimation of production functions for macrosectors 
gives elasticity estimates that lie within the range of estimates obtained from more disaggregated data, suggesting that the elasticity of demand between subsectoral goods is low.

The fourth and last finding is a small set of stylized facts, the correlation of input elasticities with sectoral characteristics as input cost shares, imbalances in input use for production, the sector value share and the sector weight in each input market. In general, an intuitive interpretation of these stylized facts is not possible because whereas the properties of a CES technology can guide us in explaining the potential effects of input elasticities on factor cost and value shares in equilibrium, explaining why these sectoral allocations would determine an exogenous parameter is a walk in the dark. An in-depth study of these correlations would be an interesting line of further research, with potential implications for the analysis of input taxation in a multisector economy. 


\section{References}

Antras, Pol, "Is the U.S. Aggregate Production Function Cobb-Douglas? New Estimates of the Elasticity of Substitution," Technical Report 2004.

Barker, Terry., Paul. Ekins, Terry. Barker, and Nick. Johnstone, Global warming and energy demand / edited by Terry Barker, Paul Ekins and Nick Johnstone ; foreword by Sir John Houghton, Routledge, London ; New York :, 1995.

Bretschger, Lucas and Sjak Smulders, "Sustainability and substitution of exhaustible natural resources," Journal of Economic Dynamics and Control, 2012, 36 (4), 536-549.

Browning, Martin, Lars Peter Hansen, and James J. Heckman, "Micro data and general equilibrium models," in John B. Taylor and Michael Woodford, eds., , Vol. 1, Part A of Handbook of Macroeconomics, Elsevier, 1999, pp. 543 - 633.

Buera, Francisco J. and Joseph P. Kaboski, "Scale and the origins of structural change," Journal of Economic Theory, 2012, 147 (2), 684-712.

Carraro, Carlo and Enrica De Cian, "Factor-Augmenting Technical Change: An Empirical Assessment," Environmental Modeling and Assessment, 2012, pp. 1-14.

Chirinko, Robert S., "[sigma]: The long and short of it," Journal of Macroeconomics, June 2008, 30 (2), 671-686.

Cooley, Thomas F., "Calibrated Models," Oxford Review of Economic Policy, 1997, 13 (3), 55-69.

de La Grandville, Olivier, "In Quest of the Slutsky Diamond," American Economic Review, June 1989, 79 (3), 468-81.

Duarte, Margarida and Diego Restuccia, "The Role of the Structural Transformation in Aggregate Productivity," The Quarterly Journal of Economics, 2010, 125 (1), 129-173.

Fiorito, Riccardo and Giulio Zanella, "The Anatomy of the Aggregate Labor Supply Elasticity," Review of Economic Dynamics, 2012, 15 (2), 171-187.

Hansen, Lars Peter and James J. Heckman, "The Empirical Foundations of Calibration," Journal of Economic Perspectives, 1996, 10 (1), 87-104.

Herrendorf, Berthold, Christopher Herrington, and Akos Valentinyi, "Sectoral Technology and Structural Transformation," CEPR Discussion Papers 9386, C.E.P.R. Discussion Papers March 2013.

Im, Kyung So, M.Hashem Pesaran, and Yongcheol Shin, "Testing for unit roots in heterogeneous panels," Journal of Econometrics, 2003, 115 (1), $53-74$.

Jin, Hui and Dale W. Jorgenson, "Econometric modeling of technical change," Journal of Econometrics, 2010, 157 (2), 205 - 219.

Jones, Charles I., "The Shape of Production Functions and the Direction of Technical Change," The Quarterly Journal of Economics, 2005, 120 (2), 517-549.

Jorgenson, Dale W. and Marcel P. Timmer, "Structural Change in Advanced Nations: A New Set of Stylised Facts," Scandinavian Journal of Economics, 03 2011, 113 (1), 1-29.

Kemfert, Claudia, "Estimated substitution elasticities of a nested CES production function approach for Germany," Energy Economics, 1998, 20 (3), 249-264. 
Klump, Rainer and Olivier de La Grandville, "Economic Growth and the Elasticity of Substitution: Two Theorems and Some Suggestions," American Economic Review, September 2000, 90 (1), $282-291$.

Koesler, Simon and Michael Schymura, "Substitution elasticities in a CES production framework: An empirical analysis on the basis of non-linear least squares estimations," Technical Report 2012.

Leon-Ledesma, Miguel A., Peter McAdam, and Alpo Willman, "Identifying the Elasticity of Substitution with Biased Technical Change," American Economic Review, 2010.

_ , _ , and _ , "Aggregation, the skill premium, and the two-level production function," Working Paper Series 1400, European Central Bank November 2011.

_ , _, and _ , "Production Technology Estimates and Balanced Growth," Oxford Bulletin of Economics and Statistics, 2013, forthcoming.

Maddala, G. S. and Shaowen Wu, "A Comparative Study of Unit Root Tests with Panel Data and a New Simple Test," Oxford Bulletin of Economics and Statistics, 1999, 61 (S1), 631-652.

Oberfield, Ezra and Devesh Raval, "Micro data and macro technology," Technical Report 2012.

Otto, Vincent M., Andreas Loeschel, and John Reilly, "Directed technical change and differentiation of climate policy," Energy Economics, 2008, 30 (6), 2855 - 2878.

Perroni, Carlo and Thomas F. Rutherford, "Regular flexibility of nested CES functions," European Economic Review, 1995, 39 (2), 335-343.

Sato, K., "A Two-Level Constant-Elasticity-of-Substitution Production Function," The Review of Economic Studies, 1967, 34 (2), 201-218.

Timmer, M.P., "The World Input-Output Database (WIOD): Contents, Sources and Methods," available at http://www.wiod.org/database/index.htm, 2012.

van der Mensbrugghe, Dominique, "The Environmental Impact and Sustainability Applied General Equilibrium (ENVISAGE) Model," Technical Report, World Bank, Washington DC 2010.

van der Werf, Edwin, "Production functions for climate policy modeling: An empirical analysis," Energy Economics, November 2008, 30 (6), 2964-2979. 


\section{A Construction of Energy Price Data}

Original price data are taken from the OECD dataset "Energy prices and Taxes". In order to build the aggregate energy price index for every country-year observation, I need prices for each major energy carrier included in the WIOD (14 selected ${ }^{11}$, covering around $70 \%$ of total energy use). The aggregate index is a weighted average of energy prices for different energy types, where weights are given by the country's energy mix (average over the sample period, to avoid that variations in weights affect the aggregate price).

OECD price data present several missing values. The highest concern is about interruptions in time series for single energy carriers because this could generate spurious variations in the aggregate index. To prevent missing data from affecting the aggregate price index over time, incomplete time series are reconstructed. Fortunately, the cases are not so many and only the energy carriers Naphtha, High Fuel Oil (HFO) and Electricity present this issue. For Naphtha and HFO, I exploit the similarity of these products to, respectively, Diesel and Light Fuel Oil (LFO), for which I have complete information. The replacement procedure is as follows. First, I calculate yearly changes for the price of the substitute energy carrier starting from the first year of missing data in the original series. The price changes are then applied to the original price series $\left\{p_{e j, t}\right\}_{t=0}^{T}$ :

$$
p_{e j, t}=\prod_{l=t_{x}}^{t}\left(\frac{p_{e h, l}}{p_{e h, l-1}}\right) p_{e j, t_{x}-1}
$$

where the price of the incomplete energy carrier $j$ (e.g. HFO) is replaced by the price of the energy carrier $h$ (e.g. LFO) and the first missing year for $j$ is period $t_{x}$. For Electricity prices, the few cases of incomplete time series are reconstructed by interpolation. However, when countries have only few available observations, no more than four years, the entire time series is considered missing and it is removed from the calculation of the price index (the quantities for the missing energy carrier are also subtracted to the total energy use before weighting).

Finally, data for some energy carriers in few countries are completely missing (first two columns in Table 5). The replacement procedure is the same, this time using information of similar countries. The matching is based on geographical and economic criteria, mostly location proximity and similarity in the national energy mix (fourth column). The third column of Table 7 lists the share of those energy carriers for year 2002, showing that missing data are not higher than one fifth of total energy use (excluded Slovenia, around $25 \%$ ).

Table 7: Missing value treatment for specific energy carriers

\begin{tabular}{cccc}
\hline Energy carrier & Missing values for & Energy share (pct, 2002) & Replaced with \\
\hline Diesel & Estonia & 4.6 & Finland \\
& Slovenia & 5.4 & Austria \\
\hline \multirow{2}{*}{ Electricity } & Estonia & 7.8 & Finland \\
& Slovenia & 13.4 & Austria \\
\hline LFO & Estonia & 5.1 & Finland \\
& Slovenia & 7.0 & Austria \\
\hline \multirow{2}{*}{ Natural Gas } & Austria & 15.7 & Hungary \\
& Belgium & 11.3 & France \\
& Portugal & 6.7 & Spain \\
& Italy & 16.6 & Spain \\
\hline
\end{tabular}

\footnotetext{
${ }^{11}$ Crude Oil, Diesel, Jet fuel, Light Fuel Oil (LFO), Heavy Fuel Oil (HFO), Naphtha, Natural Gas, Electricity and Renewables
} 


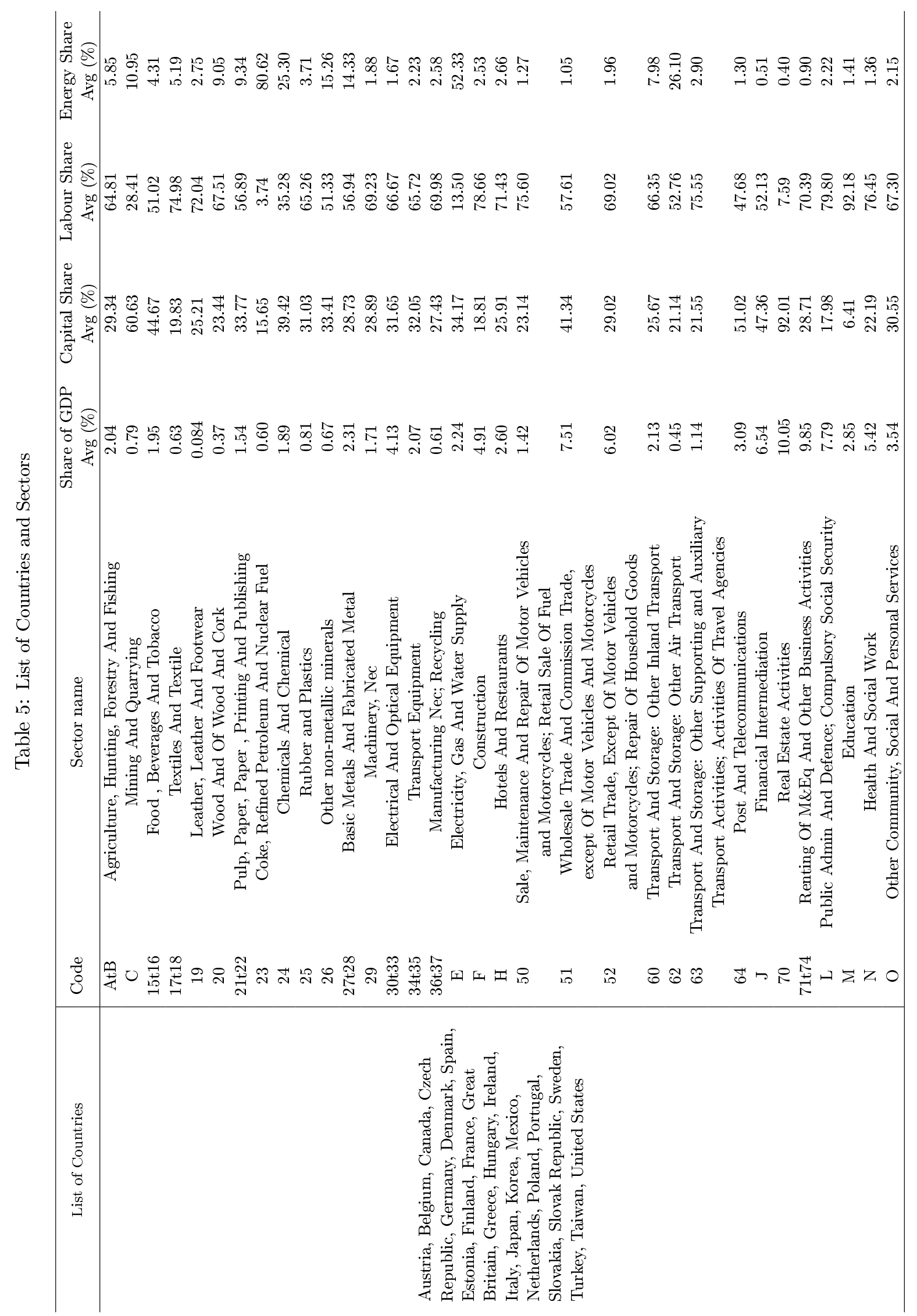


Table 6: Macrosectors - Specification

\begin{tabular}{cc} 
Macrosector & Including: \\
\hline Primary $($ Pri $)$ & AtB, C \\
Secondary $($ Sec $)$ & $15 \mathrm{t} 16-24,27 \mathrm{t} 28,29,30 \mathrm{t} 33,34 \mathrm{t} 35,36 \mathrm{t} 37, \mathrm{E}, \mathrm{F}$ \\
Tertiary $($ Ter $)$ & $50-52,60-64,70,71 \mathrm{t} 74, \mathrm{H}, \mathrm{J}, \mathrm{L}, \mathrm{M}, \mathrm{N}, \mathrm{O}$ \\
Energy-intensive $($ HighE $)$ & $\mathrm{AtB}, \mathrm{C}, 17 \mathrm{t} 18,20-24,26,27 \mathrm{t} 28, \mathrm{E}, 60-63$ \\
Low Energy Use $($ Low $)$ & $15 \mathrm{t} 16,19,25,29-36 \mathrm{t} 37,50-52,64,70,71 \mathrm{t} 74, \mathrm{~F}, \mathrm{H}, \mathrm{J}, \mathrm{L}, \mathrm{M}, \mathrm{N}, \mathrm{O}$ \\
\hline
\end{tabular}




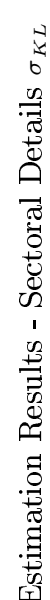

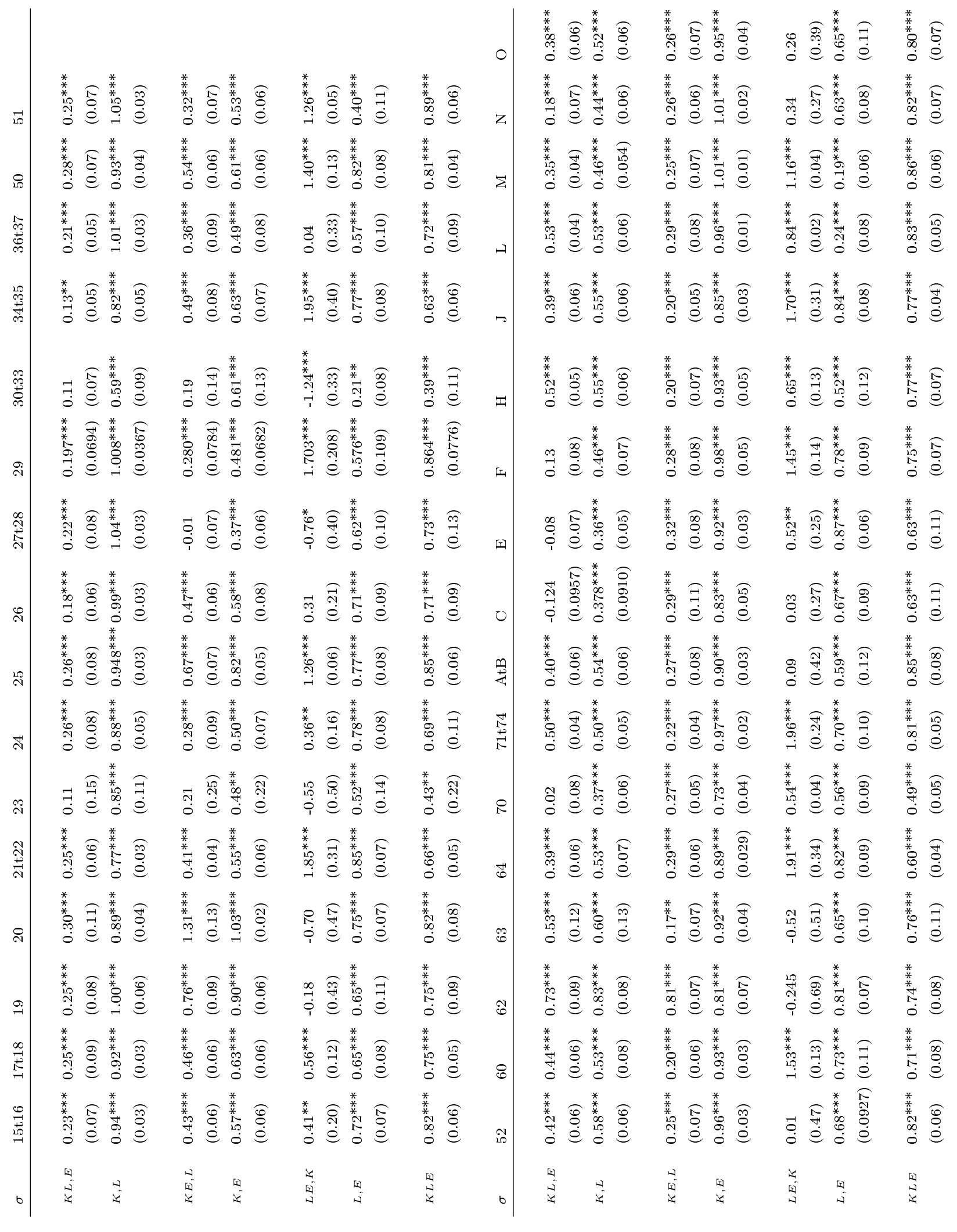

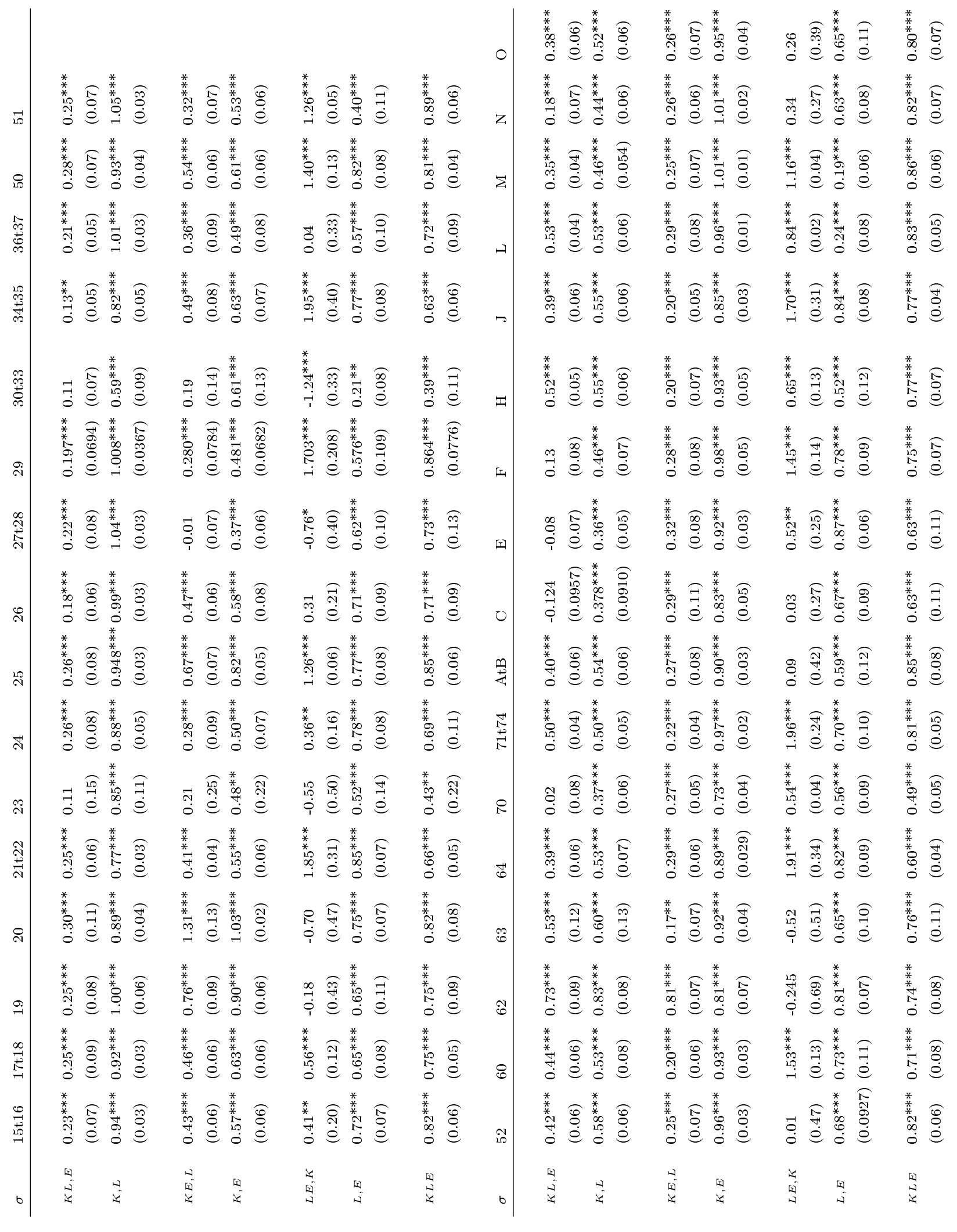

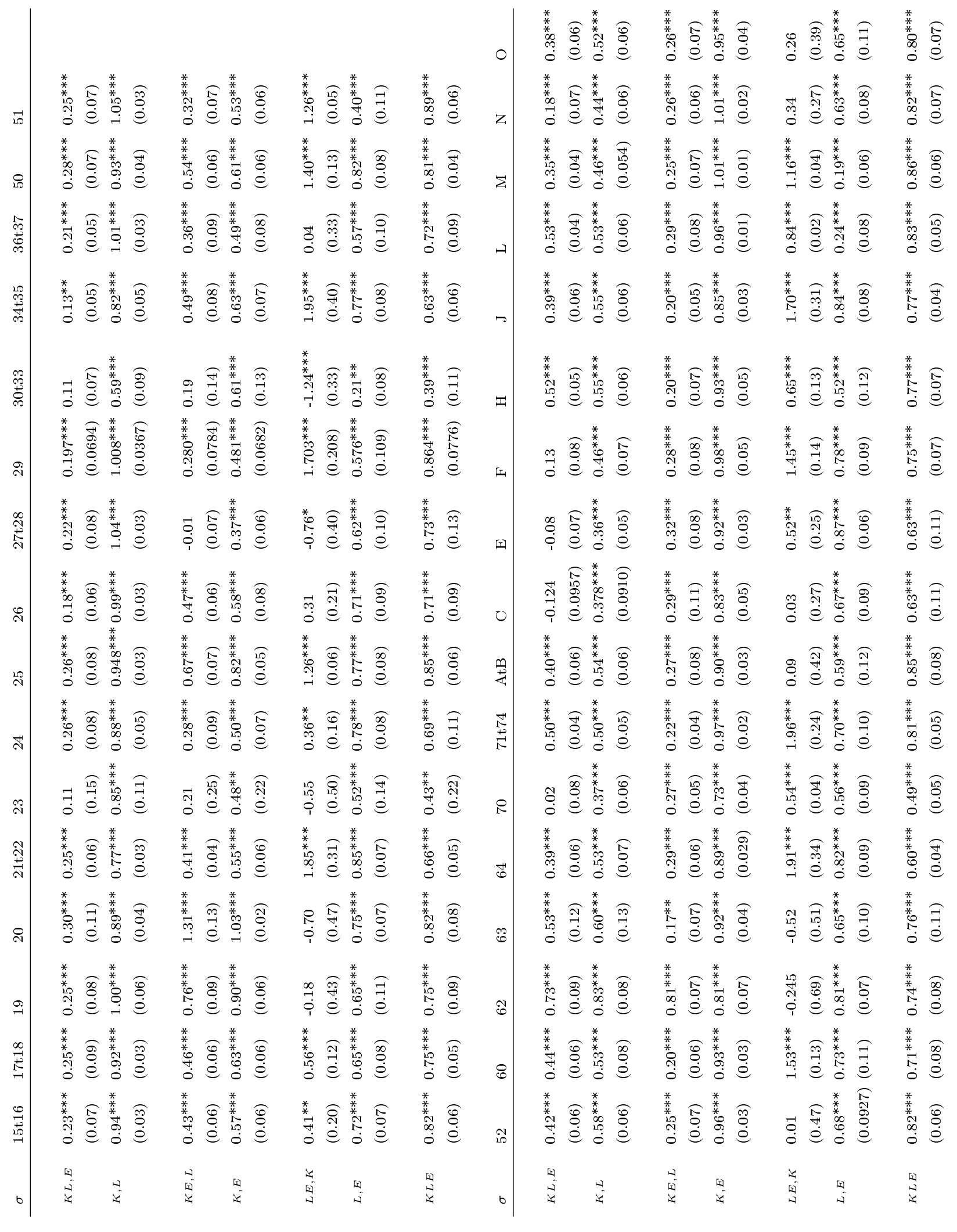

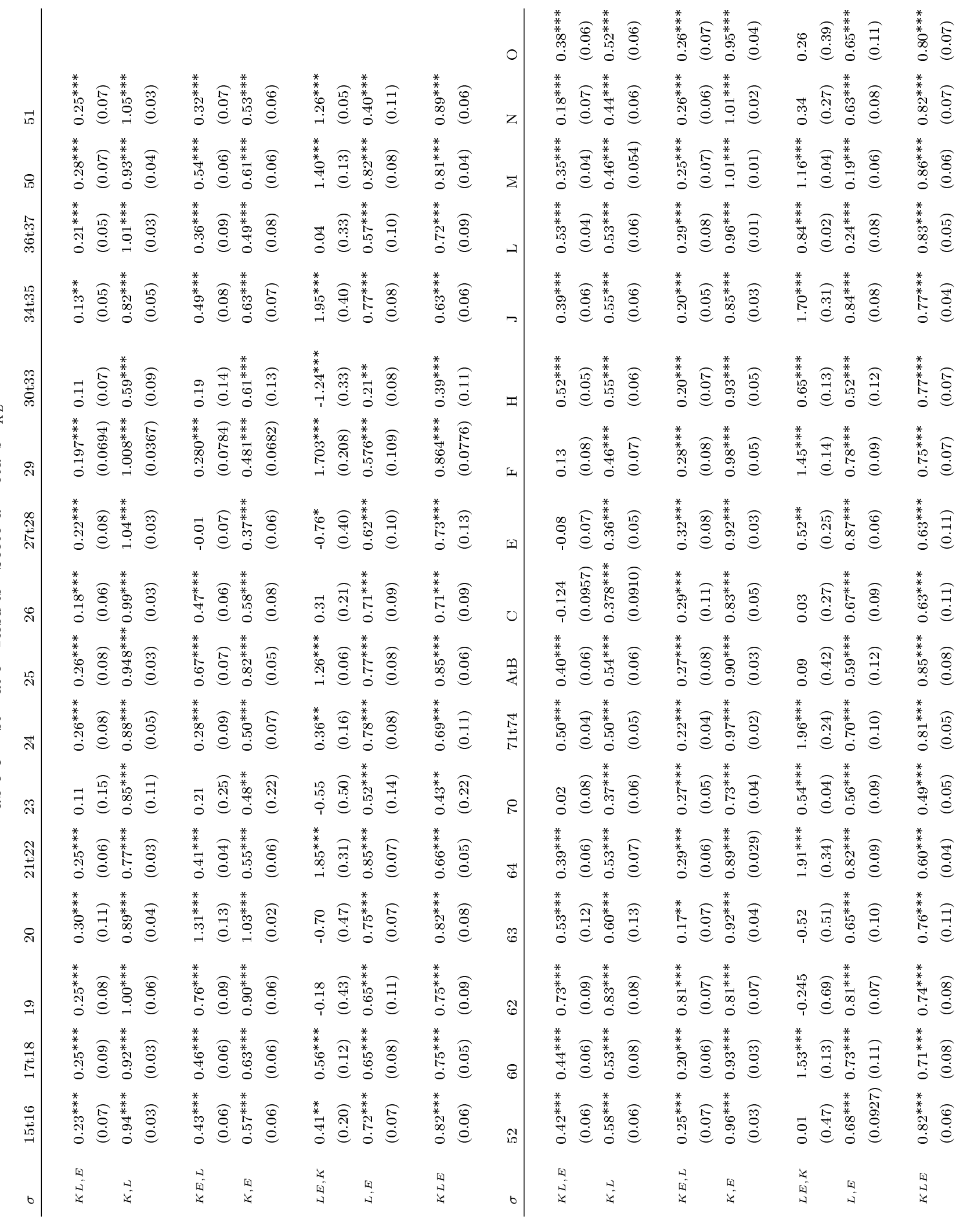




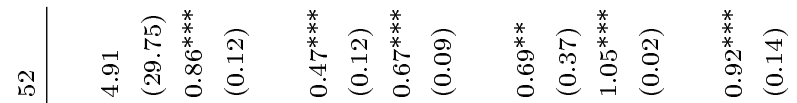

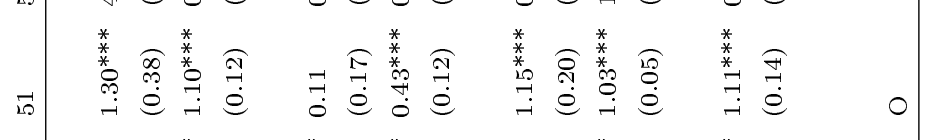

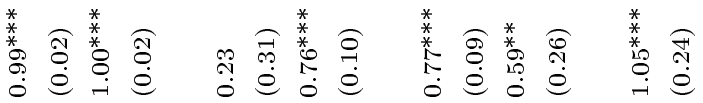

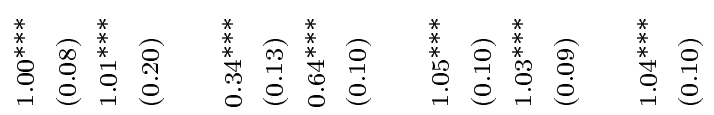

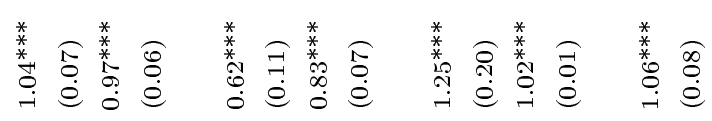

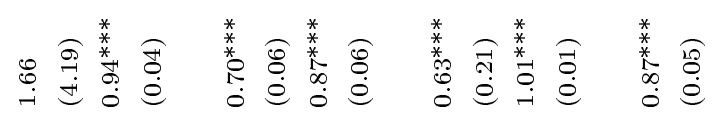

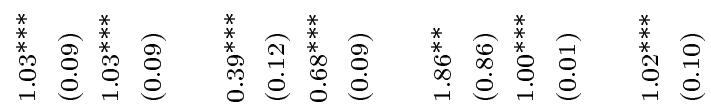

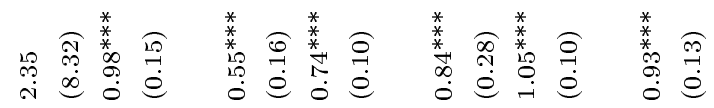

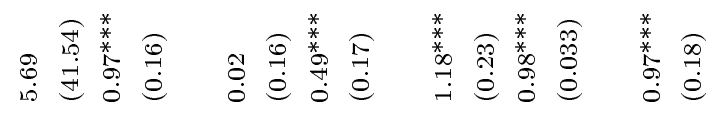

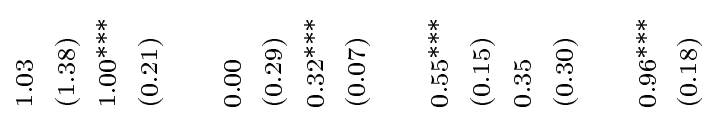

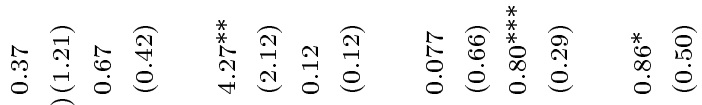

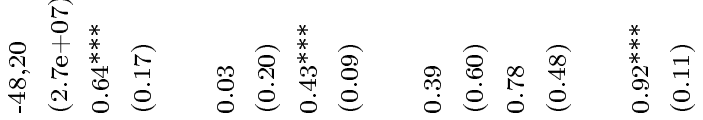

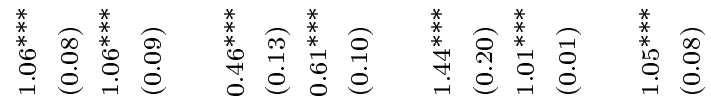

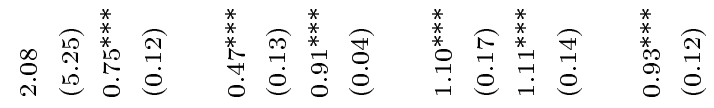

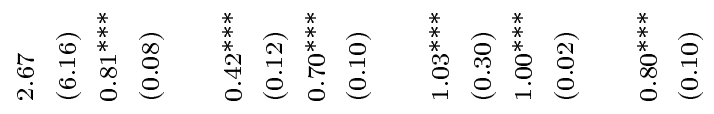

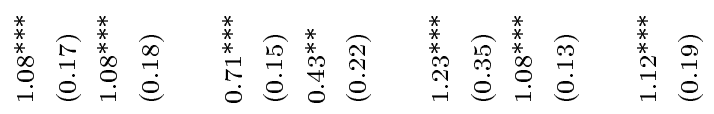

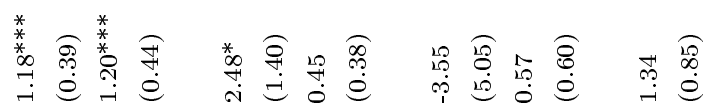

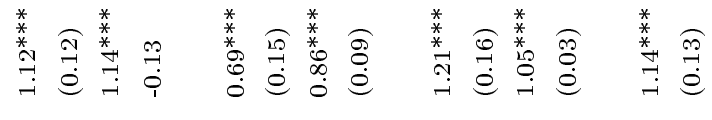

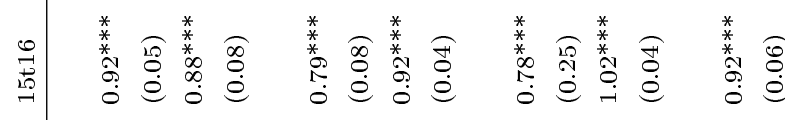
8 
Table 10: Macrosectors - Details of Estimation Results

\begin{tabular}{|c|c|c|c|c|c|c|c|}
\hline & & Primary & Secondary & Tertiary & $\begin{array}{c}\text { Energy } \\
\text { Intensive }\end{array}$ & $\begin{array}{c}\text { Low Energy } \\
\text { Use }\end{array}$ & $\begin{array}{l}\text { Aggregate } \\
\text { Economy }\end{array}$ \\
\hline \multirow[t]{3}{*}{$\sigma_{K L, E}$} & & $0.28 * * *$ & $0.23 * * *$ & $0.20 * * *$ & $0.21^{* * *}$ & $0.21^{* * *}$ & $0.21^{* * *}$ \\
\hline & & $(0.09)$ & $(0.07)$ & $(0.05)$ & $(0.06)$ & $(0.05)$ & $(0.06)$ \\
\hline & $\sigma_{K L, E}=1$ & 67.26 & 135.0 & 232.5 & 159.5 & 206.3 & 202.8 \\
\hline \multirow[t]{4}{*}{$\sigma_{K, L}$} & & $0.91^{* * *}$ & $0.95 * * *$ & $1.00 * * *$ & $0.95^{* * *}$ & $1.00 * * *$ & $0.98 * * *$ \\
\hline & & $(0.03)$ & $(0.04)$ & $(0.02)$ & $(0.03)$ & $(0.02)$ & $(0.01)$ \\
\hline & $\sigma_{K, L}=1$ & 10.29 & 1.52 & 0.06 & 3.49 & 0.00 & 0.22 \\
\hline & $J-S t a t$ & 16.5 & 2.12 & 5.53 & 4.6 & 3.91 & 7.03 \\
\hline \multirow{3}{*}{$\sigma_{K E, L}$} & & $0.29 * * *$ & $0.25^{* * *}$ & $0.42^{* * *}$ & $0.25^{* * *}$ & $0.33^{* * *}$ & $0.31^{* * *}$ \\
\hline & & $(0.06)$ & $(0.07)$ & $(0.03)$ & $(0.05)$ & $(0.05)$ & $(0.04)$ \\
\hline & $H_{0}: \sigma_{K E, L}=1$ & 122.4 & 103.2 & 302.9 & 255.1 & 204.3 & 352.7 \\
\hline \multirow[t]{4}{*}{$\sigma_{K, E}$} & & $0.46^{* * *}$ & $0.53^{* * *}$ & $0.45^{* * *}$ & $0.44^{* * *}$ & $0.46^{* * *}$ & $0.42^{* * *}$ \\
\hline & & $(0.06)$ & $(0.07)$ & $(0.04)$ & $(0.05)$ & $(0.05)$ & $(0.04)$ \\
\hline & $H_{0}: \sigma_{K, E}=1$ & 75.59 & 38.63 & 155.3 & 106.7 & 136.1 & 175.5 \\
\hline & $J$-Stat & 60.39 & 61.69 & 67.63 & 77.4 & 51.0 & 70.36 \\
\hline \multirow[t]{3}{*}{$\sigma_{L E, K}$} & & -0.21 & $-0.69^{*}$ & $1.67 * * *$ & -0.08 & $1.51 * * *$ & $1.51^{* * *}$ \\
\hline & & $(0.47)$ & $(0.38)$ & $(0.16)$ & $(0.40)$ & $(0.10)$ & $(0.14)$ \\
\hline & $H_{0}: \sigma_{L E, K}=1$ & 6.64 & 19.73 & 17.66 & 7.34 & 26.94 & 13.08 \\
\hline \multirow[t]{4}{*}{$\sigma_{L, E}$} & & $0.62 * * *$ & $0.56^{* * *}$ & $0.66^{* * *}$ & $0.59 * * *$ & $0.64 * * *$ & $0.73^{* * *}$ \\
\hline & & $(0.12)$ & $(0.08)$ & $(0.11)$ & $(0.10)$ & $(0.10)$ & $(0.09)$ \\
\hline & $H_{0}: \sigma_{L, E}=1$ & 9.76 & 28.23 & 9.99 & 15.86 & 12.23 & 9.37 \\
\hline & $J-S t a t$ & 18.71 & 32.83 & 20.57 & 25.45 & 23.99 & 20.81 \\
\hline \multirow[t]{4}{*}{$\sigma_{K E L}$} & & $0.87 * * *$ & $0.62^{* * *}$ & $0.82^{* * *}$ & $0.66^{* * *}$ & $0.75^{* * *}$ & $0.74 * * *$ \\
\hline & & $(0.10)$ & $(0.09)$ & $(0.05)$ & $(0.09)$ & $(0.06)$ & $(0.07)$ \\
\hline & $H_{0}: \sigma_{K E L}=1$ & 1.81 & 18.26 & 13.25 & 15.3 & 17.5 & 16.10 \\
\hline & $J-S t a t$ & 23.8 & 22.45 & 17.04 & 20.05 & 18.2 & 22.0 \\
\hline
\end{tabular}

Note: 337 Observations. Standard errors in parenthesis. The table also reports the the $J$-statistic and the $\chi^{2}$ statistics for the Wald test of the Cobb-Douglas hypothesis. 
Table 11: Macrosectors - Estimation with First-differenced Models

\begin{tabular}{|c|c|c|c|c|c|c|c|}
\hline & & Primary & Secondary & Tertiary & $\begin{array}{l}\text { Energy } \\
\text { Intensive }\end{array}$ & $\begin{array}{c}\text { Low Energy } \\
\text { Use }\end{array}$ & $\begin{array}{l}\text { Aggregate } \\
\text { Economy }\end{array}$ \\
\hline \multirow[t]{3}{*}{$\sigma_{K L, E}$} & & $-4,69$ & 2.31 & $1.13^{*}$ & 3.45 & $1.07^{* * *}$ & $1.02^{* * *}$ \\
\hline & & $(734,48)$ & $(7.63)$ & $(0.58)$ & $(15.41)$ & $(0.38)$ & $(0.07)$ \\
\hline & $H_{0}: \sigma_{K L, E}=1$ & 0.00 & 0.03 & 0.05 & 0.02 & 0.04 & 0.11 \\
\hline \multirow[t]{4}{*}{$\sigma_{K, L}$} & & $0.62^{* * *}$ & $0.90^{* * *}$ & $1.02^{* * *}$ & $0.86^{* * *}$ & $1.01^{* * *}$ & $0.97^{* * *}$ \\
\hline & & $(0.18)$ & $(0.09)$ & $(0.05)$ & $(0.08)$ & $(0.05)$ & $(0.04)$ \\
\hline & $H_{0}: \sigma_{K, L}=1$ & 4.5 & 1.28 & 0.16 & 2.36 & 0.05 & 0.40 \\
\hline & $J-S t a t$ & 9.44 & 0.65 & 6.18 & 0.79 & 1.54 & 5.43 \\
\hline \multirow{3}{*}{$\sigma_{K E, L}$} & & -0.04 & $0.73^{* * *}$ & $0.59 * * *$ & $0.23^{* *}$ & $0.68 * * *$ & $0.71 * * *$ \\
\hline & & $(0.19)$ & $(0.10)$ & $(0.08)$ & $(0.09)$ & $(0.08)$ & $(0.06)$ \\
\hline & $H_{0}: \sigma_{K E, L}=1$ & 28.00 & 6.88 & 23.57 & 66.12 & 13.42 & 39.93 \\
\hline \multirow[t]{4}{*}{$\sigma_{K, E}$} & & $0.38 * * *$ & $0.94^{* * *}$ & $0.73 * * *$ & $0.36^{* * *}$ & $0.84^{* * *}$ & $0.87^{* * *}$ \\
\hline & & $(0.08)$ & $(0.04)$ & $(0.09)$ & $(0.09)$ & $(0.07)$ & $(0.06)$ \\
\hline & $H_{0}: \sigma_{K, E}=1$ & 48.73 & 2.21 & 9.06 & 54.01 & 5.07 & 4.53 \\
\hline & $J-S t a t$ & 35.4 & 28.04 & 37.44 & 36.21 & 24.44 & 39.93 \\
\hline \multirow[t]{3}{*}{$\sigma_{L E, K}$} & & 0.48 & $0.94^{* * *}$ & $1.19 * * *$ & $0.72 * * *$ & $1.28^{* * *}$ & $1.06^{* * *}$ \\
\hline & & $(0.46)$ & $(0.17)$ & $(0.11)$ & $(0.27)$ & $(0.12)$ & $(0.13)$ \\
\hline & $H_{0}: \sigma_{L E, K}=1$ & 1.28 & 0.12 & 2.64 & 1.00 & 5.13 & 0.26 \\
\hline \multirow[t]{4}{*}{$\sigma_{L, E}$} & & $1.03^{* * *}$ & $1.02^{* * *}$ & $1.02^{* * *}$ & $1.15^{* * *}$ & $1.00 * * *$ & $1.02^{* * *}$ \\
\hline & & $(0.01)$ & $(0.08)$ & $(0.01)$ & $(0.21)$ & $(0.01)$ & $(0.03)$ \\
\hline & $H_{0}: \sigma_{L, E}=1$ & 2.89 & 0.10 & 6.45 & 0.50 & 0.37 & 0.76 \\
\hline & $J$-Stat & 0.27 & 2.23 & 0.26 & 1.02 & 2.65 & 1.25 \\
\hline \multirow[t]{4}{*}{$\sigma_{K L E}$} & & $0.95^{* * *}$ & $0.87^{* * *}$ & $1.05^{* * *}$ & $0.91^{* * *}$ & $1.02 * * *$ & $0.98^{* * *}$ \\
\hline & & $(0.11)$ & $(0.10)$ & $(0.05)$ & $(0.10)$ & $(0.07)$ & $(0.04)$ \\
\hline & $H_{0}: \sigma_{K E L}=1$ & 0.75 & 1.64 & 1.03 & 0.75 & 0.07 & 0.14 \\
\hline & $J-S t a t$ & 2.09 & 0.05 & 1.21 & 0.22 & 3.41 & 0.40 \\
\hline
\end{tabular}

Note: 310 Observations. Standard errors in parenthesis. The table also reports the the $J$-statistic and the $\chi^{2}$ statistics for the Wald test of the Cobb-Douglas hypothesis. 